\title{
Entrepreneurship and Technology Choice with Limited Contract Enforcement*
}

\author{
Burak R. Uras ${ }^{\dagger}$ \\ Department of Economics, Tilburg University \\ European Banking Center and CentER
}

\begin{abstract}
Cross-country data shows a strong positive correlation between the level of financial contract enforcement and macroeconomic development. This paper emphasizes the role of entrepreneurial investment technology choice in explaining this empirical observation. We develop a life-cycle model with limited financial contract enforcement, entrepreneurial heterogeneity (ability and financial pledgeability) and a discrete investment technology choice. In the model production processes can be undertaken using either a Short-Term or a Long-Term technology investment. Depending on the entrepreneurial ability, the long-term technology investment is more productive relative to the short-term investment, but the latter can be exploited to build collateral in the short-run. In equilibrium the level of contract enforcement and entrepreneurial characteristics endogenously determine (1) the investment size and (2) the investment technology choice at the firm level. Key results of the paper indicate that when financial contract enforcement is weak, the investment size and the intensity of long-term technology use of entrepreneurial firms are positively correlated with financial pledgeability. We calibrate the model to study its quantitative macroeconomic properties. Quantitative experiments illustrate sizeable positive effects of financial contract enforcement on aggregate output and aggregate long-term investment. Specifically, the counterfactual policy analysis shows that if financial contract enforcement in Turkey improves to the U.S. level, output rises by 13-15\%; and more importantly for our analysis, we can identify that one third of this change is due to the increase in the rate of long-term investment.
\end{abstract}

Keywords: Technology Choice, Collateral Building, Financial Pledgeability and Contract Enforcement.

JEL Classification Numbers: G2, O11, O33, and K12.

\footnotetext{
*Acknowledgements: I would like to thank Ping Wang, Bruce C. Petersen, Gaetano Antinolfi, Sebastian Galiani, Anne Villamil, Tiago Cavalcanti, Stephen D. Williamson, Yongseok Shin; the members of the Macroeconomics Reading Group at Washington University in St. Louis, as well as the participants of the 2010 Missouri Economics Conference at Federal Reserve Bank in St. Louis, 2010 Midwest Macroeconomics Conference at the Michigan State University, 2010 Public Economic Theory Conference at Boğaziçi University, 2011 SAET Meeting at Faro-Portugal, and seminar participants at Tilburg University, Boğaziçi University, Copenhagen Business School, University of Groningen, IfoMunich and Babson College. Financial support from the Washington University in St. Louis and Tilburg University are greatly acknowledged. All errors are mine.

${ }^{\dagger}$ Contact: Burak R. Uras, Department of Economics Tilburg University 5000 LE, Tilburg, The Netherlands. Tel: +31-6-198-06242; E-mail: R.B.Uras@uvt.nl.
} 
The basic hypothesis is that, while the total supply of entrepreneurs varies among societies, the productive contribution of society's entrepreneurial activities varies much more because of their allocation between productive and unproductive activities. This allocation is heavily influenced by the relative payoffs society offers to such activities. This implies that policy can influence the allocation of entrepreneurship more effectively than it can influence its supply.

William J. Baumol (1990)

\section{Introduction}

Limited financial contract enforcement imposes a major obstacle for economic development. La-Porta et al. [22] documents that the level of financial contract enforcement has high cross-country variation and per capita income is on average higher in economies with high contract enforcement ${ }^{1}$. Following this empirical evidence, research by Antunes et al. [2], Quintin [24], and Buera et al. [6] showed that financial contract enforcement stimulates the supply of entrepreneurship and affects measured total factor productivity by large proportions. In this paper, we study the effects of financial contract on entrepreneurial technology choice and in turn aggregate performance.

Baumol [4] points out that it is not only the overall supply of entrepreneurship that matters for a society's development process but also the way entrepreneurs allocate resources over-time and across a variety of investment projects. Therefore, we expect the desired institutions to enlarge the aggregate entrepreneurial investment while stimulating the allocation of entrepreneurial talent as well as other factors of production to productive investment areas. In this paper we have explored the implications of financial contract enforcement for investment life-cycle decisions among a distribution of entrepreneurs when long-term investment is relatively more influential for total factor productivity while short-term investment is important for short-run entrepreneurial collateral building. Our results show that improvements in financial contract enforcement stimulate entrepreneurship, decrease the entrepreneurial myopia with respect to investment horizon choice, and enhance macroeconomic development when initial level of contract enforcement is low. We show that a significant proportion

\footnotetext{
${ }^{1}$ Figure 1 in Appendix B plots the legal Rights Index developed by the World Bank against real per capita GDP. Legal rights index captures the ability to enforce collateral and bankruptcy laws of legal systems. The value indices range from 0 to 10, with higher scores indicating better enforcement.
} 
of these long-run welfare gains is due to the rise in the fraction of entrepreneurial talent allocated to long-term investment projects.

We construct an overlapping generations model with finitely-lived entrepreneurial firms which are heterogeneous in aptitude (talent) to undertake long-term investment projects and their financial pledgeability. Entrepreneurs face a discrete investment technology choice between long-term productivity enhancing investment and short-term investment. In the model, limited financial contract enforcement constrains investment opportunities of entrepreneurs with low financial pledgeability. Our analytical results show that when financial contract enforcement is weak, initial investment size and short-term investment intensity of an entrepreneurial firm is positively correlated with entrepreneur's financial pledgeability. The intuition behind these results is as the following: When financial contract enforcement is weak, financial pledgeability and physical collateral become substitutes for an entrepreneur. Therefore, with weak financial contract enforcement entrepreneurial firms which cannot start-out with optimum investment size due to low ability to pledge, have incentives to build-up collateral in the short-run to buffer future investment opportunities. In our setting, incentives to build collateral in the short-run leads to intensive short-term investment at financially constrained firms. Limited financial contract enforcement stimulates incentives to invest short-term and leaves a fraction of entrepreneurial talent associated with long-term investment unexploited. The latter effect causes a drop in macroeconomic performance which motivates our analysis in this paper. To study the aggregate implications of financial contract on macroeconomic development, we conduct a quantitative analysis. Quantitative experiments suggest two important effects of financial contract enforcement: (1) Economies with weak contract enforcement are characterized with low per capita income and low long-term investment. (2) A rise in contract enforcement creates a reallocation of resources from large firms to small firms while also stimulating the aggregate long-term investment at small-scale enterprises. We also study a counterfactual policy exercise where we calibrate the steady state equilibrium of the model for Turkish (a relatively low enforcement economy) and the U.S. (a relatively high enforcement economy) data. Our results show that, if the financial contract enforcement level of Turkey improves to the U.S. level, per-capita output rises by 13-15\%; and central for our analysis about one third of this change is due to the increase in the rate of aggregate long-term investment.

Investment longevity affects entrepreneurial returns through various channels. R\&D investment, investment in entrepreneurial human capital, and modern technology adoption are one way or an- 
other associated with long-term investment. Therefore, the intensity of long-term investment at entrepreneurial firms not only affects the firm-level productivity but also the aggregate total factor productivity. We present the following empirical evidence to motivate the argument that financial contract enforcement is influential for the aggregate long-term investment: Figure 2 plots for 36 countries the ratio between the average information technology (IT) investment and the aggregate physical investment for the 1985-1993 time period against contract enforcement levels of each country in this sample. IT investment, which can be considered as a type of long-term technology investment for the 1985-1993 period, was undertaken intensely in countries where financial contract enforcement was high. The close similarity between figure 1 (GDP against contract enforcement) and figure 2 (IT investment intensity against contract enforcement) indicates that the lack of willingness to invest long-term among developing nations might be important in explaining the role of contract enforcement for macroeconomic development ${ }^{2}$.

\section{Related Literature}

The argument that "entrepreneurial incentives are important in structural transformation of countries from low-income, primary-based societies to high income-technology based societies" dates back to Schumpeter [27]. Following Schumpeterian proposition, an extensive literature studied the role of entrepreneurship in macroeconomic development: The seminal articles by Lucas [19] and Kihlstrom and Laffont [17] are the first studies of entrepreneurship in general equilibrium theory. Other important papers on entrepreneurship and macroeconomics are Cagetti and De Nardi [7] (entrepreneurship and wealth distribution), Jiang et al. [28] (entrepreneurship and ability heterogeneity), and Newman [20] (entrepreneurship and risk taking). Evans and Jovanovic [12], and Hurst and Lusardi [14] are classical studies on financial constraints and entrepreneurial decision making.

There is also a large literature which studies the effects of institutions on entrepreneurial productivity. In this respect, Baumol [4] is a seminal article which suggest that although increasing the amount of resources allocated to private entrepreneurs is important for a society's well being, much more critical is the way the private sector uses up these resources. According to Baumol's hypothesis, what matters is not "who gets what" but "who gets what and how does he use it". Secure property rights (Wiggens [29]) and rule of law (Parker [21]) are expected to be important institutions in allocating

\footnotetext{
${ }^{2}$ There is substantial empirical evidence for the underlying micro implications of the model as well: Using U.S. manufacturing data, Romeo [26], Kelley and Brooks [16], and Dunne [11] show that plant size and long-term technology use are correlated for collateral poor small scale entrepreneurial firms.
} 
entrepreneurs away from unproductive forms of entrepreneurship towards productive entrepreneurship. In this paper, we study the effects of institutional design on "productive entrepreneurship" as well, but different from the above mentioned studies in our framework we have a macro-development point of view. The institution of interest in our paper is "financial contract enforcement". Therefore, our research is related to the growing literature focusing on the effects of financial frictions, and in particular the financial contract enforceability, on entrepreneurship and aggregate economic performance. Quadrini [23], Cagetti and De Nardi [7], and Buera et al. [6] study the effects of limited contract enforcement on entrepreneurial wealth accumulation and aggregate saving dynamics. Cooley et al. [9] uncovers how limited enforceability is related with entrepreneurial commitment to investment projects and aggregate volatility. Antunes et al. [2], Quintin [24], and Buera et al. [6] study the quantitative implications of limited contract enforcement for occupation choice and the efficiency of aggregate capital allocation across entrepreneurs by emphasizing the misallocation inefficiencies due to lack of financial contract enforcement ${ }^{3}$. As in Antunes et al. [2], Quintin [24] and Buera et al. [6], we concentrate on the effects of limited contract enforcement for entrepreneurship and aggregate resource allocation as well; however, our objective differs from these studies as we study the implications of limited contract enforcement not only for the aggregate misallocation of capital among a distribution of entrepreneurs, but we also incorporate the firm specific effects of contract enforcement on the allocation of entrepreneurial talent and capital across different investment opportunities.

The paper is organized as follows. Section 2 develops the theoretical framework. Sections 3 presents the optimal behavior and the general equilibrium of the model. Section 4 extends the benchmark model to incorporate partnership formations and studies the effects of financial contract enforcement on intergenerational trade of long term investment projects. Section 5 presents the quantitative analysis of the model. Section 6 concludes.

\section{The Model}

Time is discrete and continues forever as $t=0,1,2,3 \ldots$. The economy is populated by 3 -period-lived overlapping generations, in addition to the initial old and the initial middle-aged agent at $t=0$. The

\footnotetext{
${ }^{3}$ The seminal works on misallocation and aggregate economic performance are Restuccia and Rogerson [25] and Hsieh and Klenow [13].
} 
population is constant where every period a continuum of young agents with a unit measure enter the economy. There are two types of agents in the model: financiers and entrepreneurs. There is a single good in the economy which can be consumed, stored, or invested.

\subsection{Economic Agents}

\subsubsection{Financiers}

An agent becomes a financier with an exogenously given probability $\mu$ at the beginning of his lifetime, and inherits a "Lucas tree". The "Lucas Tree" generates a consumption good flow at the beginning of the financier's lifetime. The consumption good flow is homogeneous among entrepreneurs and without loss of generality it is normalized to 1 . The consumption good is perfectly divisible; any fraction of it can be stored, lent or consumed. The consumption good does not depreciate, therefore it can be stored for multiple periods, setting the lower-bound one-period (short-term) interest rate to 1. Denote $c^{y}, c^{m}$ and $c^{o}$ as consumption at youth, middle-age and old respectively. Financiers born in period $t$ have preferences over the consumption good in the following way:

$$
U_{F}\left(c_{t}^{y}, c_{t+1}^{m}, c_{t+2}^{o}\right)=\phi u\left(c_{t+1}^{m}\right)+(1-\phi) u\left(c_{t+2}^{o}\right)
$$

Where $u($.$) is a concave utility function with u^{\prime}()>$.0 and $u^{\prime \prime}() \leq$.0 . Financiers do not get utility from the first period consumption. $\phi$ is a random variable standing in for a preference shock in the following way:

$$
\phi=\left\{\begin{array}{cc}
1 & \text { with probability } \pi \\
0 & \text { with probability }(1-\pi)
\end{array}\right\}
$$

The probability of getting hit by the shock is $\pi$. Depending on the realization of the shock, some financiers need to consume (early) when they are middle aged and do not get any utility from the third period consumption. Financiers who do not get hit by the preference shock, get utility from the third period consumption only. The realization of $\phi$ is publicly observable because bank-runs are not the purpose of this study. The expected lifetime utility of a financier born in period $t$ can be written as:

$$
W\left(c_{t}^{y}, c_{t+1}^{m}, c_{t+2}^{o}\right)=\pi u\left(c_{t+1}^{m}\right)+(1-\pi) u\left(c_{t+2}^{o}\right) .
$$




\subsubsection{Entrepreneurs}

An agent becomes an entrepreneur with probability $(1-\mu)$ at the beginning of his lifetime. Entrepreneurs produce the consumption good by undertaking investment projects. Unlike financiers, entrepreneurs do not have any physical wealth to begin with, therefore they borrow in the financial market to produce the consumption good. Entrepreneurs are risk neutral and care about the third period consumption only. Each entrepreneur is endowed with one unit of indivisible human (entrepreneurial) capital which is essential for the production process.

Entrepreneurs have access to investment projects when young and middle aged. Each investment project is operated by a single entrepreneur at a given period in time. There are two types of investment projects the indivisible entrepreneurial capital can be allocated at: the Long-Term investment technology (Technology-L) and the Short-Term investment technology (Technology-S). We assume that the long-term investment, or Technology-L, is associated with a longer gestation period and therefore it requires two periods to be completed, and requires an initial investment of long-term funds. Short-term investment, or Technology-S, resolves in one period and can be operated using short-term investable funds. Throughout the paper, we use the concepts "technology-S project" and "short-term investment project", and "technology-L project" and "long-term investment project" interchangeably.

Chart 1 summarizes the lifetime entrepreneurial investment opportunities for the benchmark model ${ }^{4}$.

Chart 1. Technology Choice.

\section{Short-Term Investor}

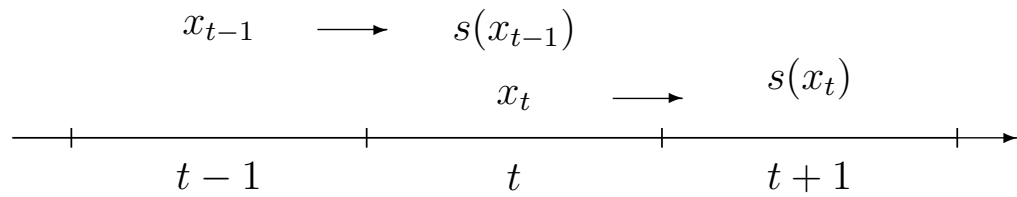

Long-Term Investor

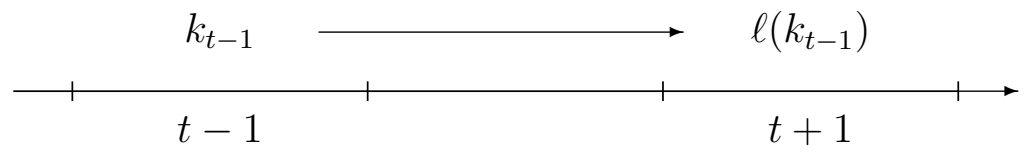

\footnotetext{
${ }^{4}$ Section 4 extends the model in such a way that entrepreneurs have the option to switch to long-term investment projects even if they have started with short term investment opportunities at the beginning of their career. In the benchmark model, entrepreneurs who start up with one type of technology, continue to use the same technology throughout their lifetime.
} 
Technology-S and technology-L investment opportunities are characterized as the following: Consider a young entrepreneur $i$ born in period $t-1$. If he chooses to invest in a long-term investment opportunity $k_{t-1}$ amount of consumption good, after two periods namely in period $t+1$, the entrepreneur collects:

$$
\ell_{i}\left(k_{t-1}\right)=\theta_{i} f\left(k_{t-1}\right)
$$

In this functional form $\theta_{i}$ represents a publicly observable and independently and identically distributed entrepreneurial quality parameter setting entrepreneur specific long-term project aptitude. The parameter $\theta_{i}$ is distributed with the cumulative distribution function $F(\theta)$ across young entrepreneurs with support $[0, \bar{\theta}]$. The quality parameter $\theta$ is constant throughout the lifetime of an entrepreneur. The return function $f($.$) is strictly concave in the usual sense that f(.)^{\prime}>0$ and $f^{\prime \prime}() \leq$.0 . If we denote $R_{2}^{i}(t-1)$ as the non-negative long-term gross interest rate charged to entrepreneur $i$, the profit function associated with long-term investment becomes:

$$
\max _{k_{t-1}}\left\{\ell_{i}\left(k_{t-1}\right)-R_{2}^{i}(t-1) k_{t-1}\right\}
$$

If a young entrepreneur $j$ chooses to invest $x_{t-1}$ amount of consumption good in short-term investment technology in period $t-1$, after one period in period $t$ he collects:

$$
s_{j}\left(x_{t-1}\right)=z_{j} A f\left(x_{t-1}\right),
$$

In this functional form, the parameter $z_{j}$ stands for a technology-S specific publicly observable ${ }^{5}$ iid productivity shock with $z_{j} \in\left\{z_{g}, z_{b}\right\}$ and $z_{g}>z_{b}$. The parameter $A$ is a technology-S specific productivity parameter, with $z_{g} A<\bar{\theta}$ which implies that a fraction of entrepreneurs are more productive in conducting long-term investment projects. Denote $x_{t-1}$ as the total capital investment in the short-term project in period $t-1$. Note that $x$ and $k$ denote the same type of good, but for notational convenience different letters are assigned to the capital used by the two different investment opportunities. If we denote $R_{1}^{j}(t-1)$ as the non-negative short-term gross interest rate charged to the entrepreneur $j$, then

\footnotetext{
${ }^{5}$ At the beginning of an entrepreneur's lifetime.
} 
the profit maximization for the short-term investor $j$ becomes:

$$
\max _{x_{t-1}}\left\{s_{t j}\left(x_{t-1}\right)-R_{1}^{j}(t-1) x_{t-1}\right\} .
$$

When the short-term investor entrepreneur $j$ becomes middle-aged in period $t$ he has the option to re-invest in a secondary short-term project using the technology-S. The returns to the second investment accrue according to the following return function:

$$
s_{j}\left(x_{t}\right)=A f\left(x_{t}\right) .
$$

Returns of the second period short-term investment project get realized in period $t+1$ when the entrepreneur is old. To account for experience development through subsequent project investment, the return realization on short-term investment projects are assumed to be not subject to idiosyncratic productivity shocks.

\subsection{The Financial Market}

Lenders and borrowers interact directly in the financial market by trading short-term and long-term investable funds. Credit market imperfections generate endogenous debt constraints and constrain market transactions in the following way: Financial contract enforcement is limited in the economy. This means borrowers cannot commit not to default on repayment. If entrepreneurs default, a firm specific fraction of production returns can be seized by courts (institutions which enforce financial contracts) and transferred to lenders. Limited enforceability generates financial constraints as in the Kehoe and Levine [15] framework which represent incentive compatibility constraints. Different from the Kehoe and Levine [15] setting though, in the current model borrowers are not excluded from the credit market upon defaulting. Specifically, incentive compatibility constraints for a young entrepreneur $j$ have the following form:

$$
\begin{aligned}
\frac{\lambda_{j}^{S}}{\zeta} z_{j} A f(m) & \geq R_{1}^{j} m \\
\frac{\lambda_{j}^{L}}{\zeta} \theta_{j} f(m) & \geq R_{2}^{j} m
\end{aligned}
$$


Inequality (3) is the financial constraint associated with short-term investment, whereas inequality (4) is the financial constraint associated with long-term investment. Financial constraints (3) and (4) are interpreted as the following: If an entrepreneur chooses not to commit to his repayment, the lender can seize only a fraction $\frac{\lambda_{j}^{k}}{\zeta}$ of the entrepreneur's end of investment period final output. Here, $\lambda$ measures entrepreneur's perceived financial pledgeability in the financial market, which is iid, has a cumulative distribution function $G(\lambda)$ over $[0, \bar{\lambda}]$, and publicly observable. The higher $\lambda$ associated with an entrepreneur, the lower is the entrepreneur's financial pledgeability. The distribution of pledgeability levels across entrepreneurs have implications for the aggregate economic performance when financial constraints are binding for at least a fraction of the entrepreneurs in an economy.

On the other hand, $1 / \zeta$ is an economy-wide parameter and measures how effectively financial contracts are enforced by society's institutions. Constraints (3) and (4) are structured in such a way that, the higher an entrepreneur's short-term, $z_{j}$, and/or long-term, $\theta_{j}$, productivity the larger is the amount he can borrow in the financial market to invest in any type of investment project. Therefore, collateral building ability is correlated with productivity which is an empirically plausible assumption.

For a middle-aged entrepreneur the second period short-term investment opportunity is constrained in the following way if he chooses to invest short-term during the first period of his lifetime:

$$
\frac{\lambda_{j}^{S}}{\zeta} A f(m) \geq R_{1}^{j}(m-n)
$$

In inequality (5) $m$ is the working capital invested and $n$ is the amount of earnings retained (internal finance) if the entrepreneur has chosen to have a short-term investment horizon when he was young. The internal finance generated by the first period short term investment project is the "collateral built" by the entrepreneurial firm.

Assumption 1. $\lambda_{j}^{S}=\min \left\{a, \lambda_{j}\right\}, \lambda_{j}^{L}=\lambda_{j}$, with $a>0$.

Assumption 1 implies that entrepreneurs with very low levels of $\lambda$ can borrow slightly more if they would go for short-term borrowing. This mechanism resembles a microcredit institution, a la Buera et al. [5], upon which small scale entrepreneurial firms heavily rely if the society-wide financial contract enforceability is too low. 
Since in the financial market information, and pledgeability levels get realized before financial market transactions, the following result follows immediately:

Lemma $2.1 R_{1}^{j}=R_{1}$ and $R_{2}^{j}=R_{2}$ for every entrepreneur $j$.

Proof Suppose there is an entrepreneur $i$ and an entrepreneur $j$ such that $R_{k}^{i}>R_{k}^{j}$ where $k \in$ $\{1,2\}$. Since no-arbitrage does not hold in this case, financiers compete to lend to entrepreneur $i$ because $E_{f}\left[R_{k}^{i}\right]>E_{f}\left[R_{k}^{j}\right]$, where $E_{f}\left[R_{k}^{i}\right]$ stands in for expected returns from entrepreneurial financing. Competition will diminish the interest rate gap between the two entrepreneurs until $R_{1}^{j}=R_{k}$ holds. $\square$

Time-line of Events. The flow of events in a given period $t$ are as the following: At the beginning of period $t$, preference shocks of middle-aged financiers who were born in period $t-1$ get realized. After that, entrepreneurs collect returns from period $t-1$ short-term investment (S.T.) projects and returns from period $t-2$ long-term (L.T.) projects. Debt repayment takes place, and agents consume. Productivity and pledgeability levels of young entrepreneurs get publicly realized after consumption takes place. Entrepreneurs sell financial claims against future investment returns. And finally, young and middle aged entrepreneurs start to produce. Chart 2 summarizes the flow of events.

Chart 2. Flow of Events.

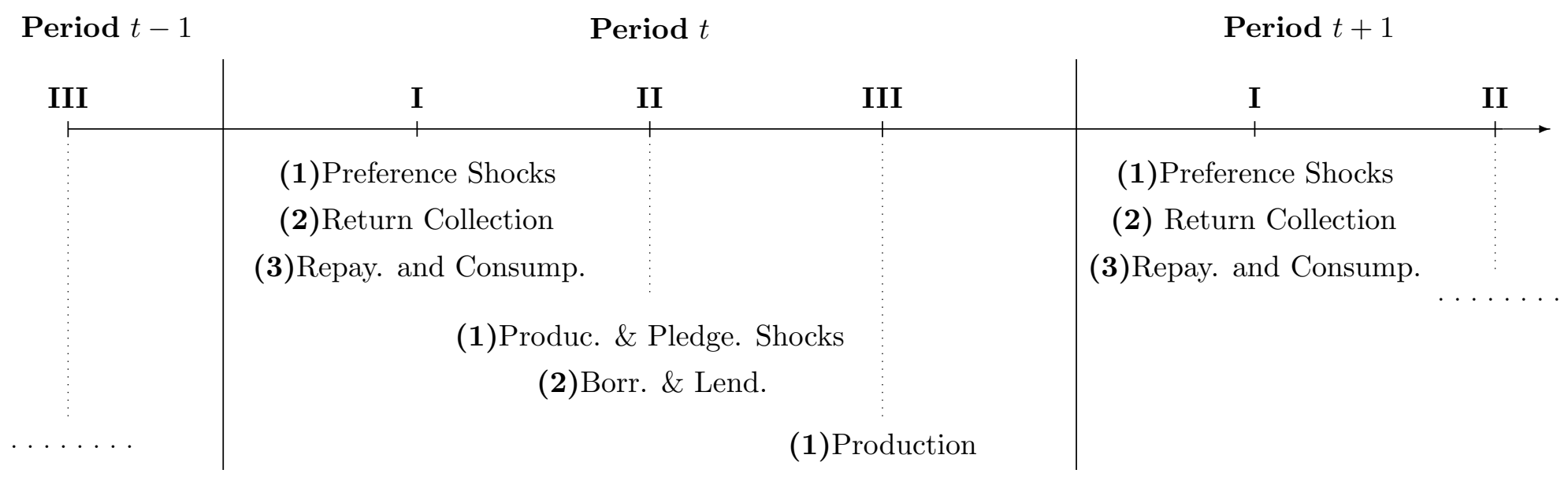




\section{Optimal Behavior and General Equilibrium}

\subsection{Financier's Program}

Financier's consumption optimization problem, when $d$ denotes the share of financier's funds allocated to short-term lending, is given as:

$$
\begin{aligned}
W\left(c^{m}, c^{o}\right) \equiv \max _{c^{m}, c^{o}, d} & \pi u\left(c^{m}\right)+(1-\pi) u\left(c^{o}\right) \\
\text { s.t. } & c^{m} \leq R_{1} d \\
& c^{o} \leq\left(R_{1}\right)^{2} d+R_{2}(1-d)
\end{aligned}
$$

To maximize lifetime utility, financiers decide on the optimum fraction of investable funds to lend as short-term $\left(d^{o p t}\right)$ and long-term $\left(1-d^{o p t}\right)$. Returns from the first period short term lending can be used to finance short term projects in the following period. When $u(c)=\ln (c)$ we can derive financier's maximization problem as:

$$
W\left(d^{o p t}\right) \equiv \max _{d}\left\{\pi \log \left(d R_{1}\right)+(1-\pi) \log \left(d\left(R_{1}\right)^{2}+(1-d) R_{2}\right)\right\}
$$

Taking first order conditions yields optimum share of funds allocated to short-term lending. If $R_{1}$ and $R_{2}$ are greater than 1 , and $R_{2}>\left(R_{1}\right)^{2}$ :

$$
d^{o p t}=\frac{\pi R_{2}}{R_{2}-\left(R_{1}\right)^{2}}
$$

Proposition 3.1 If $R_{2} \leq\left(R_{1}\right)^{2}$ then $d^{\text {opt }}=1$. If $R_{2}>\left(R_{1}\right)^{2}$, then $d^{o p t}$ is increasing in the short-term interest rate $\left(R_{1}\right)$, the probability of getting hit by an adverse liquidity shock $(\pi)$, but decreasing in the long-term interest rate $\left(R_{2}\right)$.

\subsection{Entrepreneur's Program}

A young entrepreneur has to decide: (1) the investment project and hence the investment horizon, and (2) the size of the capital investment. Investment decisions are made recursively. Taking the optimum short-term investment size $\left(x_{1}^{\text {opt }}\right.$-optimum size of the first period short-term investment and 
$x_{2}^{o p t}$-optimum size of the second period short-term investment) and the optimum long-term investment size $\left(k^{\text {opt }}\right)$ as given a young entrepreneur compares the lifetime value functions associated with shortterm investment $\left(V^{S}\right)$ and long-term investment $\left(V^{L}\right)$, and optimally choose the investment horizon:

$$
\max \left\{V^{S}\left(x_{1}^{o p t}, x_{2}^{o p t}\right), V^{L}\left(k^{o p t}\right)\right\}
$$

Dropping the time subscripts and applying the result obtained in lemma 2.1, for an entrepreneur $j$ the optimum short-term capital investment levels are determined by taking first order conditions at the following maximization problem:

$$
\begin{aligned}
V^{S}\left(x_{1}^{\text {opt }}, x_{2}^{\text {opt }}\right) \equiv \max _{x_{1}, x_{2}} \quad & \left\{R_{1}\left(z_{j} A f\left(x_{1}\right)-R_{1} x_{1}\right)+A f\left(x_{2}\right)-R_{2} x_{2}\right\} \\
\text { s.t. } & \frac{\lambda_{j}^{S}}{\zeta} z_{j} A f\left(x_{1}\right) \geq R_{1} x_{1} \\
& \frac{\lambda_{j}^{S}}{\zeta} A f\left(x_{2}\right) \geq R_{1}\left(x_{2}-z_{j} A f\left(x_{1}\right)+R x_{1}\right)
\end{aligned}
$$

On the other hand, the optimum long-term capital investment level is determined by solving:

$$
\begin{aligned}
V^{L}\left(k^{o p t}\right) \equiv \max _{k} & \left\{\theta_{j} f(k)-R_{2} k\right\} \\
\text { s.t. } & \frac{\lambda_{j}^{L}}{\zeta} \theta_{j} f(k) \geq R_{2} k
\end{aligned}
$$

(8) and (9) are financial constraints associated with short-term investment, whereas (11) is the financial constraint associated with short-term investment.

Remark An immediate result is as the following: financial pledgeability and firm size are positively correlated. The RHSs of constraints in (8), (9) and (11) are decreasing in $\lambda_{j}$ and $1 / \zeta$, whereas the LHSs are constant. Therefore, heterogeneity in pledgeability is a determinant of firm size whenever financial constraints become binding.

Assuming $f(m)=m^{\alpha}$ for $m \in\{x, k\}$ with $0<\alpha<1$, and defining $\lambda^{*}$ and $\lambda^{* *}$ as two critical levels of entrepreneur specific financial pledgeability, the following lemma shows that we can characterize three types of entrepreneurs depending on their level of financial pledgeability.

Lemma 3.2 (1) There exist threshold levels $\lambda^{*}\left(z_{j}\right)$ for $z_{j} \in\left\{z_{g}, z_{b}\right\}$, such that constraint (9) is binding 
when

$$
\lambda_{j} \leq \lambda^{*}\left(z_{j}\right)
$$

with

$$
\lambda^{*}\left(z_{g}\right) \leq \lambda^{*}\left(z_{b}\right)
$$

(2) There exists a threshold $\lambda^{* *}$ such that constraints (8) and (11) are binding when

$$
\lambda_{j} \leq \lambda^{* *}
$$

with

$$
\lambda^{* *}>\lambda^{*}\left(z_{b}\right)
$$

Proof All proofs can be found in Appendix A.

Given $z_{j}, \lambda^{*}\left(z_{j}\right)$ and $\lambda^{* *}$ partitions the space of entrepreneurs into three categories with respect to the level of pledgeability: Low pledgeability, intermediate level pledgeability and high pledgeability; or in other words entrepreneurs who are financially constrained when young and middle aged, entrepreneurs who are financially constrained only when young, and finally entrepreneurs who are never financially constrained.

Assumption 2: The lower bound a is small enough $(a \leq \underline{a})$ such that only the entrepreneurs in "low pledgeability" group have a relatively low financial pledgeability if they invest short-term.

Using assumption 2 and the results from lemma 3.2 we can characterize value functions associated with short-term and long-term investment for each pledgeability category.

\section{Entrepreneurs with high financial pledgeability:}

The following value functions are associated with entrepreneurs for whom $\lambda_{j} \geq \lambda^{* *}$ holds. Using the unconstrained optimum capital investment levels we can characterize:

$$
\begin{aligned}
V^{S}\left(x_{1}^{* *}, x_{2}^{* *}\right) & =(1-\alpha)\left[\left(z_{j} A\right)^{\frac{1}{1-\alpha}} R_{1}\left(\frac{\alpha}{R_{1}}\right)^{\frac{\alpha}{1-\alpha}}+A^{\frac{1}{1-\alpha}}\left(\frac{\alpha}{R_{1}}\right)^{\frac{\alpha}{1-\alpha}}\right] \\
V^{L}\left(k^{* *}\right) & =(1-\alpha) \theta_{j}^{\frac{1}{1-\alpha}}\left(\frac{\alpha}{R_{2}}\right)^{\frac{\alpha}{1-\alpha}}
\end{aligned}
$$


An entrepreneur with high level financial pledgeability will choose to invest using long-term technology if his entrepreneurial quality $\theta_{j}$ is greater than a threshold $\underline{\theta}^{h}$ :

$$
\theta_{j} \geq \underline{\theta}^{h} \equiv A\left[z_{j}^{\frac{1}{1-\alpha}} R_{1}\left(\frac{R_{1}}{R_{2}}\right)^{\frac{\alpha}{1-\alpha}}+\left(\frac{R_{1}}{R_{2}}\right)^{\frac{\alpha}{1-\alpha}}\right]^{(1-\alpha)}
$$

Note that $\left(1-F\left(\underline{\theta}^{h}\right)\right)$ determines the fraction of high pledgeability entrepreneurs who are willing to undertake long-term investment projects; $\left(1-F\left(\underline{\theta}^{h}\right)\right)$ also sets the benchmark aggregate long-term investment intensity. In a frictionless economy (high $1 / \zeta$ such that constraints (8), (9) and (11) do not bind), a fraction $\left(1-F\left(\underline{\theta}^{h}\right)\right)$ of the entrepreneurial population chooses to invest in the long-term technology. Financial constraints generated by weak contract enforcement or low financial pledgeability create deviations from the benchmark investment composition.

\section{Entrepreneurs with intermediate levels of financial pledgeability:}

When constraint (8) is binding, but (9) is not $\left(\lambda^{* *} \geq \lambda_{j} \geq \lambda^{*}\left(z_{j}\right)\right)$, value functions associated with short-term and long-term investment can be characterized as the following;

$$
\begin{aligned}
V^{S}\left(x_{1}^{*}, x_{2}^{* *}\right) & =\left(1-\frac{\lambda_{j}}{\zeta}\right)\left(z_{j} A\right)^{\frac{1}{1-\alpha}} R_{1}\left(\frac{\lambda_{j}}{\zeta R_{1}}\right)^{\frac{\alpha}{1-\alpha}}+(1-\alpha) A^{\frac{1}{1-\alpha}}\left(\frac{\alpha}{R_{1}}\right)^{\frac{\alpha}{1-\alpha}} \\
V^{L}\left(k^{* *}\right) & =\left(1-\frac{\lambda_{j}}{\zeta}\right) \theta_{j}^{\frac{1}{1-\alpha}}\left(\frac{\lambda_{j}}{\zeta R_{2}}\right)^{\frac{\alpha}{1-\alpha}}
\end{aligned}
$$

An entrepreneur with an intermediate level financial pledgeability will choose to operate a long-term investment project if his long-term project quality $\theta_{j}$ is greater than $\underline{\theta}^{m}\left(\lambda_{j} ; \zeta\right)$ :

$$
\theta_{j} \geq \underline{\theta}^{m}\left(\lambda_{j} ; \zeta\right) \equiv A\left[z_{j}^{\frac{1}{1-\alpha}} R_{1}\left(\frac{R_{1}}{R_{2}}\right)^{\frac{\alpha}{1-\alpha}}+\frac{1-\alpha}{1-\frac{\lambda_{j}}{\zeta}}\left(\frac{\zeta \alpha}{\lambda_{j}}\right)^{\frac{\alpha}{1-\alpha}}\left(\frac{R_{1}}{R_{2}}\right)^{\frac{\alpha}{1-\alpha}}\right]^{(1-\alpha)}
$$

\section{Proposition 3.3}

(i.) $\underline{\theta}^{m}\left(\lambda_{j} ; \zeta\right)$ is monotonically decreasing in $\lambda_{j}$ for $\lambda_{j} \in\left(\lambda_{j}^{*}\left(z_{j}\right), \lambda_{j}^{* *}\right)$.

(ii.) $\underline{\theta}^{m}\left(\lambda_{j} ; \zeta_{1}\right)>\underline{\theta}^{m}\left(\lambda_{j} ; \zeta_{2}\right)$ for $\zeta_{1}>\zeta_{2}$

(iii.) $\underline{\theta}^{m}\left(\lambda_{j} ; \zeta\right) \geq \underline{\theta}^{h}$ for all $\lambda_{j} \in\left(\lambda_{j}^{*}\left(z_{j}\right), \lambda_{j}^{* *}\right)$.

The results in proposition 3.3 show that financial constraints not only limit the investment size 
but also influence the investment horizon choice of an entrepreneur. Entrepreneurs, whose financial pledgeability take intermediate values may switch to operate long-term investment projects when they become more pledgeable. $\underline{\theta}^{m}\left(\lambda_{1} ; \zeta\right) \leq \underline{\theta}^{m}\left(\lambda_{2} ; \zeta\right)$ for $\lambda_{1} \geq \lambda_{2}$, which implies that the measure of entrepreneurs investing long-term whose pledgeability level is $\lambda_{1}\left(\left(1-F\left(\underline{\theta}^{m}\left(\lambda_{1} ; \zeta\right)\right)\right)\right.$ is greater than the the measure of entrepreneurs investing long-term whose pledgeability level is $\lambda_{2}\left(\left(1-F\left(\underline{\theta}^{m}\left(\lambda_{2} ; \zeta\right)\right)\right)\right.$. Entrepreneurs with intermediate levels of pledgeability are constrained during the first period of their lifetime, but they become unconstrained during the second period if they have chosen to operate shortterm investment projects when young. However, if they invest long-term, financial constraints affect their lifetime investment opportunities. There is a complementarity between the size of the investment and the long-term technology use because the life-cycle feature of the model generates a "collateral building" role associated with short-term investment which distorts entrepreneurial incentives to undertake long-term investment opportunities. The desire for internalization of investable funds during the early phase of investment activity is similar to the "collateral effect" in Kiyotaki and Moore [18]. Because of the declining benefits associated with collateral building, entrepreneurs switch to long-term investment as their pledgeability increases and/or the economy-wide limited contract enforcement improves. Therefore, entrepreneurs who are at the low end of the distribution within "intermediate levels of financial pledgeability entrepreneurs" choose to invest short-term more intensely relative to those who are at the high end of the same distribution. The third result obtained in proposition 3.3 shows that, because of the collateral building effect the aggregate long-term investment intensity of entrepreneurs with intermediate levels of pledgeability is below the benchmark aggregate long-term investment intensity, that is for each $\lambda_{j} \in\left[\lambda^{*}\left(z_{j}\right), \lambda^{* *}\right]$, we have $\left(1-F\left(\underline{\theta}^{m}\left(\lambda_{j} ; \zeta\right)\right)<\left(1-F\left(\underline{\theta}^{h}\right)\right)\right.$.

\section{Entrepreneurs with low financial pledgeability:}

Finally if both (8) and (9) are binding $\left(\lambda_{j} \leq \lambda^{*}\left(z_{j}\right)\right)$, the optimum size of the first period short-term investment in technology-S is given by $x_{1}^{*}=\left(\frac{\lambda_{j} z_{j} A}{\zeta R_{1}}\right)^{\frac{1}{1-\alpha}}$, whereas the optimum size of the second period short-term investment is

$$
x_{2}^{*}=h\left(\lambda_{j}, z_{j}\right)
$$

Lemma $3.4 h\left(\lambda_{j}, z_{j}\right)$ is non-decreasing in both $\lambda_{j}$ and $z_{j}$. 
For an entrepreneur with low financial pledgeability, optimum long-term capital investment is given by

$$
k^{*}=\left(\frac{\lambda_{j} \theta_{j}}{\zeta R_{2}}\right)^{\frac{1}{1-\alpha}}
$$

For low financial pledgeability entrepreneurs lifetime value functions associated with short-term and long-term investment can be derived as the following:

$$
\begin{aligned}
V^{S}\left(x_{1}^{*}, x_{2}^{*}\right) & =\left(1-\frac{\lambda_{j}}{\zeta}\right)\left(z_{j} A\right)^{\frac{1}{1-\alpha}} R_{1}\left(\frac{\lambda_{j}}{\zeta R_{1}}\right)^{\frac{\alpha}{1-\alpha}}+A h\left(\lambda_{j}, z_{j}\right)^{\frac{\alpha}{1-\alpha}}-R_{1} h\left(\lambda_{j}, z_{j}\right)^{\frac{1}{1-\alpha}} \\
V^{L}\left(k^{*}\right) & =\left(1-\frac{\lambda_{j}}{\zeta}\right) \theta_{j}^{\frac{1}{1-\alpha}}\left(\frac{\lambda_{j}}{\zeta R_{2}}\right)^{\frac{\alpha}{1-\alpha}}
\end{aligned}
$$

Using the value functions associated with short-term and long-term investment evaluated at respective optimum investment levels, an entrepreneur with low financial pledgeability chooses to operate a long-term investment project only if:

$$
\theta_{j} \geq \underline{\theta}^{l}\left(\lambda_{j} ; \zeta\right)
$$

\section{Proposition 3.5}

i. There exists a critical level pledgeability $\lambda^{c}$, such that for all low pledgeability entrepreneurs with $\lambda_{j} \leq \lambda^{c}, \underline{\theta}^{l}\left(\lambda_{j} ; \zeta\right)$ is constant in $\lambda_{j}$, and for all entrepreneurs with $\lambda_{j} \geq \lambda^{c}, \underline{\theta}^{l}\left(\lambda_{j} ; \zeta\right)$ is monotonically decreasing in $\lambda_{j}$.

ii. When $\lambda_{j} \leq \lambda^{c}$, then $\underline{\theta}^{l}\left(\lambda_{j} ; \zeta\right)$ is constant in $\zeta$. For $\lambda_{j}>\lambda^{c}, \underline{\theta}^{l}\left(\lambda_{j} ; \zeta\right)$ is increasing in $1 / \zeta$.

Proposition 3.5 shows that, for each $\lambda_{j} \in\left[0, \lambda^{*}\left(z_{j}\right)\right]$, the measure of entrepreneurs who invest in long-term investment projects is smaller than the measure of entrepreneurs with any "intermediate" level of financial pledgeability who are willing to undertake long-term investment opportunities. If there are incremental improvements in pledgeability of a low pledgeability entrepreneur or if there are improvements in the economy-wide contract enforceability, the probability of long-term investment tendency for such an entrepreneur increases only if the level of his pledgeability is above the critical value $\lambda^{c}$. As we have shown, diminishing returns to scale associated with both types of investment projects along with the existence of a lower bound pledgeability " $a$ " for short-term borrowing is important for this result. 
Pledgeability plays a crucial role in determining investment size and investment composition of financially constrained firms. Proposition 3.3 together with proposition 3.5 prove that entrepreneurs with low pledgeability have smaller scales of production and they are short-term oriented, hence invest relatively more in short-term production technologies compared to entrepreneurs with high levels of financial pledgeability. Define $1-\Theta\left(\lambda_{j}\right)$ as the fraction of entrepreneurs investing long-term for a given level of pledgeability $\lambda_{j}$. Keeping interest rates constant, table 1 reports the main analytical results.

The aggregate investment composition depends on endogenous cut-off points $\lambda^{c}$ and $\lambda^{* *}$. The effects of limited contract enforcement on these two cut-offs are as follows:

Proposition 3.6 If $1 / \zeta$ (the strength of contract enforcement) increases cut-off points $\lambda^{c}$ and $\lambda^{* *}$ decline, and as a result the aggregate long-term investment intensity of the economy increases.

Figure 3 draws intensity of long-term investment as a function of financial pledgeability for three economies: A high-contract-enforcement economy (AHA Curve), a low-contract-enforcement economy (ALA Curve), and the perfect enforcement economy (PA). AHA curve lies above ALA curve which implies that high contract enforcement economy is characterized with higher aggregate long-term investment intensity.

One should note that the aggregate effects of financial contract enforcement are twofold: First, as the strength of contract enforcement improves, per capita income increases which eliminates the returns to collateral building, and entrepreneurs switch to long-term investment projects. Second, when using the technology-L, entrepreneurs get to exploit their intrinsic ability, and become more productive. Therefore, in the presence of a technology choice as described above, the level of economic development determines the entrepreneurial willingness to use technology-L which further feeds back into the level of macroeconomic development.

The analytical results show that our model can mimic the firm level technology use behavior for the U.S. economy, and also the correlation between the aggregate long-term technology investment intensity and contract enforceability. At the firm level small scale enterprises entrepreneurial firms in this model choose to invest in long-term technological opportunities less often compared to large scale companies. This finding corroborates with empirical results documented by by Romeo [26], Kelley and Brooks [16], and Dunne [11]. Using U.S. manufacturing data, Romeo [26], Kelley and Brooks [16] show that larger scale establishments employ more advanced and long-term technologies relative to small 
Table 1: Enforcement and Investment Composition

\begin{tabular}{|c|c|c|c|c|}
\hline \multirow{2}{*}{$\begin{array}{c}\text { Increase } \\
\text { in }\end{array}$} & \multicolumn{2}{|c|}{$1-\Theta\left(\lambda_{j}\right)$ of Low Pledge. } & $1-\Theta\left(\lambda_{j}\right)$ of Interm. Pledge. & $1-\Theta\left(\lambda_{j}\right)$ of High Pledge. \\
\cline { 2 - 5 } & $\lambda_{j} \leq \lambda^{c}$ & $\lambda^{c} \leq \lambda_{j} \leq \lambda^{*}$ & $\lambda^{*} \leq \lambda_{j} \leq \lambda^{* *}$ & $\lambda_{j} \geq \lambda^{* *}$ \\
\hline$\lambda_{j}$ or $1 / \zeta$ & No Change & Increases & Increases & No Change \\
\hline
\end{tabular}

scale enterprises. Dunne [11] shows that plant size is positively correlated with long-term technology diffusion whereas plant age and long-term technology adoption are not correlated. At the aggregate level, high contract enforceability is associated with long-term technology adaptability. This model does not associate long-term technology use with high uncertainty, risk or large set-up costs which qualifies our setting as a conservative benchmark. Long-term investment horizons associated with long-term technology investment are enough to generate our analytical results.

Figure 3. Effects of Enforceability on Technology Use

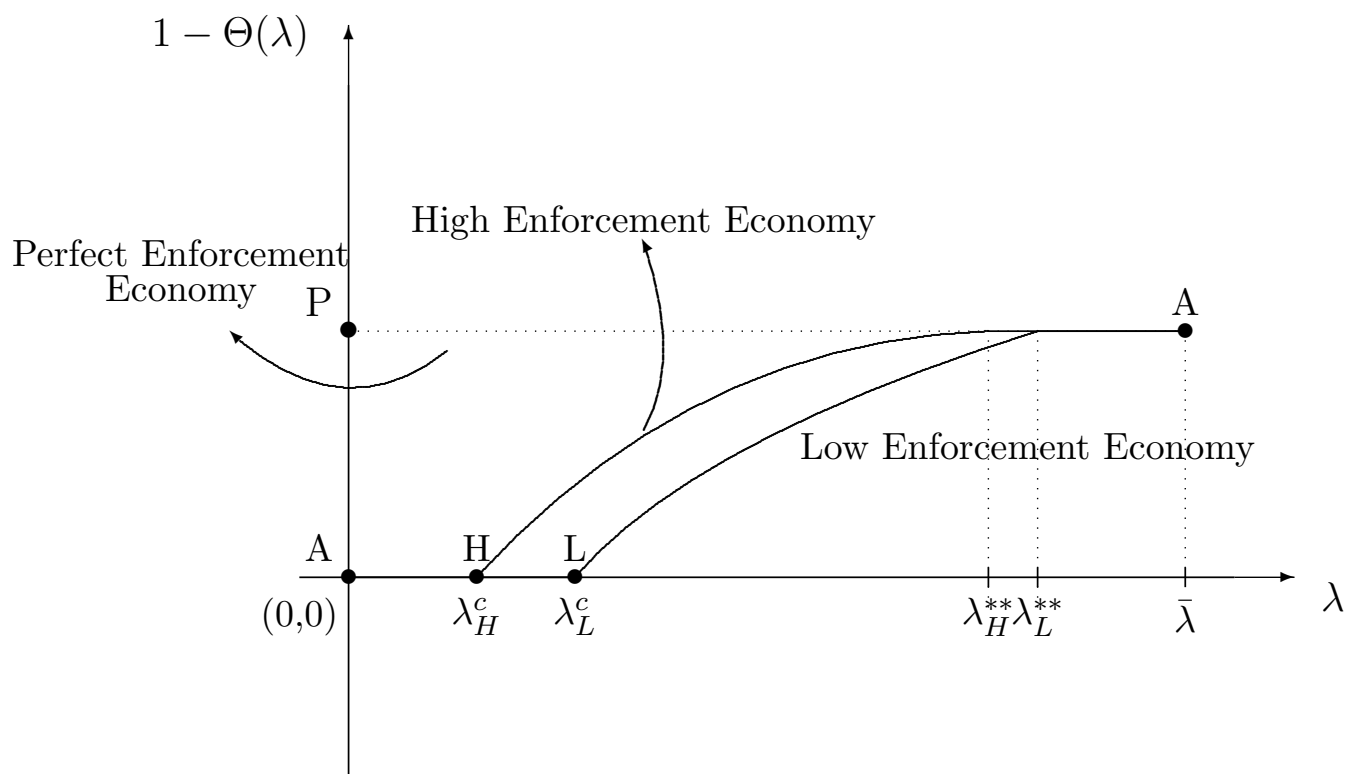

\subsection{General Equilibrium}

Definition Denote $S^{S}\left(R_{1}^{*}, R_{2}^{*}\right)$ and $S^{L}\left(R_{1}^{*}, R_{2}^{*}\right)$ as the supply of short term and the long-term loanable funds respectively, and $D^{S}\left(R_{1}^{*}, R_{2}^{*}\right)$ and $D^{L}\left(R_{1}^{*}, R_{2}^{*}\right)$ as the demand for short term and the long-term loanable funds. The steady state equilibrium of the economy is given by constant short term $\left(R_{1}^{*}\right)$ and long-term $\left(R_{2}^{*}\right)$ interest rates at which agents optimize and markets clear in the following way:

$$
\begin{aligned}
& S^{S}\left(R_{1}^{*}, R_{2}^{*}\right)=D^{S}\left(R_{1}^{*}, R_{2}^{*}\right) \\
& S^{L}\left(R_{1}^{*}, R_{2}^{*}\right)=D^{L}\left(R_{1}^{*}, R_{2}^{*}\right)
\end{aligned}
$$


Proposition 3.7 The steady state equilibrium of the economy exists and it is unique and is characterized by $\left\{R_{1}^{*}\right\}_{t}=R_{1}^{*}$ and $\left\{R_{2}^{*}\right\}_{t}=R_{2}^{*}$ for all $t^{6}$.

\section{Tradable Long-Term Investment Projects}

In this section we extend the benchmark model developed in section 3 by allowing partnership formations over long-term investment projects. This extension is important to take into consideration because it allows "collateral building" in such a way that an entrepreneur can start-up with low productivity short-term technology projects, build up collateral, and later on switch to long-term technology investment projects where he can exploit his entrepreneurial quality. Such tradability of long-term projects can be thought of as an "equity financing" option for entrepreneurial firms.

Chart 3. Technology Choice with Partnerships.

\section{S. Term/S.Term}

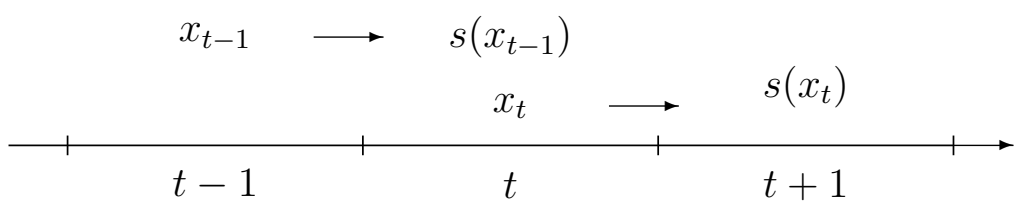

\section{L.Term}

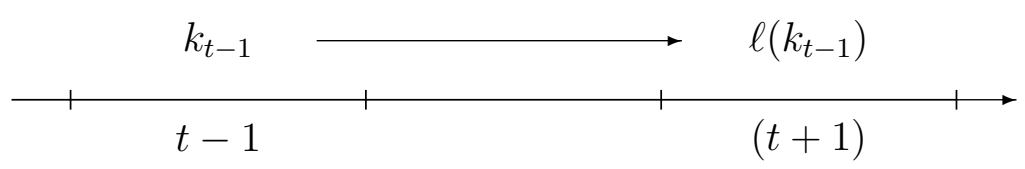

S.Term/L.Term

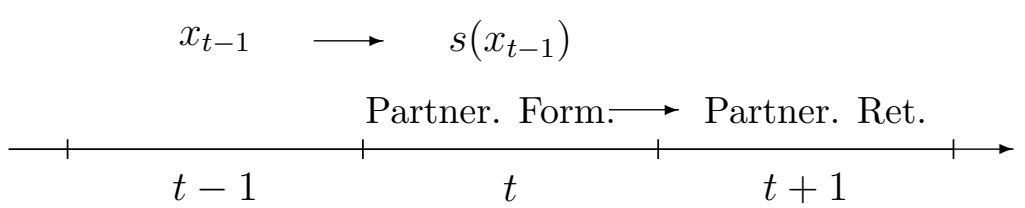

Specifically, suppose at the beginning of each odd-numbered period after productivity and pledgeability levels get realized, entrepreneurs who are willing to form a partnership meet in a partnership market. Each two-partner owned long-term project is started up by a "primary partner", who is in

\footnotetext{
${ }^{6}$ Two types of equilibria can be characterized in this setting. In the first case: $R_{2}^{*}=\left(R_{1}^{*}\right)^{2}=1$, which emerges when the demand for loanable funds is too small, making a positive fraction of financier use storage technology in equilibrium. Very weak contract enforce-ability can be a cause for this type of an equilibrium, in which incremental changes in contract enforceability do not have any effect on equilibrium interest rates. When contract enforcement is sufficiently strong the second type of equilibrium can prevail where $R_{2}^{*}>R_{1}^{*} \geq 1$. In this case there is adequate demand for both types of capital (short-term and long-term); and in this case incremental changes in contract enforceability affect both short-term and long-term interest rates.
} 
charge of the project during its first period. During the second period of the project, the "secondary partner" takes over and finishes the investment project. Therefore, in the partnership market middle aged entrepreneurs (potential primary partners) meet with young entrepreneurs (potential secondary partners).

In the partnership market, potential primary partners make contract offers to potential secondary partners. If a young entrepreneur rejects the contract offer the primary partner can instantaneously make another offer to the same young agent, or move to someone else. Potential primary partners can make infinitely many offers, and common knowledge of rationality applies. Contract offers are settled in terms of the consumption good transfers to be made to the secondary partner at the end of his lifetime, which is denoted with $\tau$. Secondary partner receives the profits from the long-term project. Once both agents agree on contractual terms, partnership contracts are perfectly enforceable. As the primary partner works on the long-term project during the first period of the partnership, the secondary partner operates a short-term investment project. When a partnership is formed, from that point on financiers see the two partners as a single entity (a joint venture). The productivity level of the long-term project initiated by the joint venture $\left(\theta_{v}\right)$ is determined as $\theta_{v}=\min \left\{\theta_{p}, \theta_{s}\right\}$ where $\theta_{p}$ is the entrepreneurial quality of the primary entrepreneur and $\theta_{s}$ is the quality of the secondary entrepreneur. Any borrowing made by the potential partners after the joint venture is formed is subject to the pledgeability constraint of the joint venture which is determined as $\lambda_{v}=\min \left\{\lambda_{p}, \lambda_{s}\right\}$. Entrepreneurs may leave the market without forming a partnership. In this default case unmatched middle-aged entrepreneurs operate short-term investment projects, and unmatched young entrepreneurs operate short-term or long-term projects.

Time-line of Events. The flow of events in an odd numbered period $t$ and in an even numbered period $t+1$ are slightly differen from each other. (i) At the beginning of period $t$ (odd numbered), first preference shocks of financiers born in period $t-1$ get realized. (ii) After that, entrepreneurs collect project returns from period $t-1$ short-term investment projects and returns from period $t-2$ long-term projects. (iii) Debt repayment takes place, and agents consume. (iv) Productivity and pledgeability levels of young entrepreneurs get publicly observed after consumption takes place. (v) Partnership market opens, middle aged and young agents contract on partnership terms, once contracts are settled entrepreneurs sell financial claims against future investment returns. (vi) Young and middle aged entrepreneurs start to produce. 
In period $t+1$ (even numbered), after short-term and long-term returns get collected middle aged partners (young in $t$ ) transfer wealth to old partners. The timeline of events after this point on is the same as in period $t$ except the partnership market does not open during the even numbered period $t+1$. Chart 4 summarizes the flow events in an economy where partnership formations are allowed.

\subsection{A Partnership Equilibrium}

We assume that contractual terms get determined such that the primary and the secondary partners share the surplus generated by the partnership with equal division which is sufficient for the existence of stationary equilibria. I am not interested in analyzing commitment problems associated with partnership formations, because it is not the purpose of this paper to characterize a broad set contractual relationships. In this section, what we would like to emphasize is that some entrepreneurs can start-up with low productivity technology-S investment projects, build up collateral, and later on switch to technology-L investment projects where they can exploit their entrepreneurial quality. The following proposition provides an equilibrium characterization for the joint venture productivity and pledgeability levels ${ }^{7}$.

Chart 4. Flow of Events.

Period $t-1$

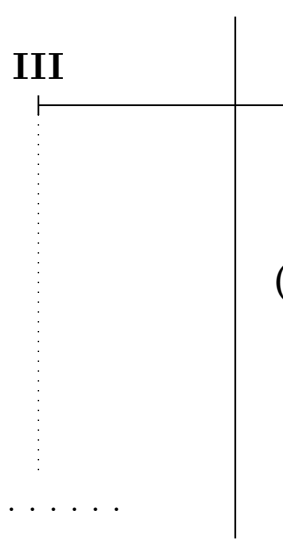

Period $t$

(2)Return Collection

(2)Return Collection

(3)Repay. and Consump.

(1)Produc. \& Pledge. Shocks

(2)Partner. Form.

(3)Borr. \& Lend.
Period $t+1$

I

II

(1)Preference Shocks

(2) Return Collection

(3)Partner. Trans.

(4)Repay \& Consump.

(1)Production

Proposition 4.1 Every middle aged entrepreneur $\left(\theta_{i}, \lambda_{i}\right)_{t}$ born in period $t$, gets matched with his identical twin, $\left(\theta_{i}, \lambda_{i}\right)_{t+1}$, from the younger generation. The implied productivity and pledgeability of the joint venture are given as $\theta_{v}=\theta_{i}$, and $\lambda_{v}=\lambda_{i}$ respectively.

\footnotetext{
${ }^{7}$ Again, there are other equilibria which may arise in this setting. But we study the properties of the most intuitive and analytically the most tractable one to serve the purpose of the paper.
} 


\subsection{Entrepreneur's Program}

\subsubsection{Profitable Partnerships}

Consider a middle-aged entrepreneur $\left(\theta_{i}, \lambda_{i}\right)_{t}$, born in period $t$, who has invested short-term when he was young. In odd-numbered periods middle aged entrepreneurs get to make contract offers to young entrepreneurs. The middle aged entrepreneur $\left(\theta_{i}, \lambda_{i}\right)_{t}$ has two options in period $t+1$ if $t$ is even: (1) Investing in a short-term investment project again, or (2) Forming a partnership with his identical twin from the younger generation and starting up a long-term investment project. Whether he will choose the latter option over the former depends on the amount of monetary transfers, $\tau$, the secondary partner can promise to make him. Of course, $\tau$ depends on the amount of accumulated wealth of the potential secondary partner from his first period short-term investment project and the secondary partner's ability to borrow against the future returns of the joint venture. We assume that at the end of the first period of a two-period-long partnership, the secondary partner can borrow against the $\lambda_{i} / \zeta$ fraction of the previously unpledgeable part of the future investment returns.

Using the results obtained in section 3 (optimum capital investment levels $\left(x_{1}^{\text {opt }}, x_{2}^{\text {opt }}\right.$, and $k^{\text {opt }}$ ) for constrained and unconstrained entrepreneurs), and the result in proposition 4.1, we can derive an upper bound for the transfers $\tau$ :

$$
\tau \leq \bar{\tau} \equiv \underbrace{\left[s\left(x_{1}^{\text {opt }}\left(\lambda_{i} ; z_{i}\right)\right)-R_{1} x_{1}^{\text {opt }}\right]}_{m_{1} \equiv 2^{\text {nd }} \text { partner's income }}+\underbrace{\left[\frac{\lambda_{i}}{R_{1} \zeta}\left(1-\frac{\lambda_{i}}{\zeta}\right) \ell\left(k_{2}^{\text {opt }}\left(\lambda_{i} ; \theta_{i}\right)\right)\right]}_{b \equiv \text { borrowings against future returns }}
$$

As one can observe the right hand side of the inequality increases in the level of entrepreneurial pledgeability and economy-wide contract enforcement. A middle aged entrepreneur chooses to become the primary partner of a long-term project only if:

$$
\left(R_{1}-1\right) m_{1}+s\left(x_{2}^{o p t}\left(\lambda_{i} ; z_{i}\right)\right)-R_{1}\left(x_{2}^{o p t}-m_{1}\right) \leq\left[\frac{\lambda_{i}}{R_{1} \zeta}\left(1-\frac{\lambda_{i}}{\zeta}\right) \ell\left(k_{2}^{o p t}\left(\lambda_{i} ; \theta_{i}\right)\right)\right]
$$

Similarly a young agent $\left(\theta_{i}, \lambda_{i}\right)_{t+1}$ agrees on to be the partner of his identical $\left(\theta_{i}, \lambda_{i}\right)_{t}$ twin from the older generation if:

$$
\left(R_{1}-1\right) m_{1}+s\left(x_{2}^{o p t}\left(\lambda_{i} ; z_{i}\right)\right)-R_{1}\left(x_{2}^{o p t}-m_{1}\right) \leq\left[\left(1-\frac{\lambda_{i}}{\zeta}\left(1-\frac{\lambda_{i}}{\zeta}\right)\right) \ell\left(k_{2}^{o p t}\left(\lambda_{i} ; \theta_{i}\right)\right)-R_{2} k_{2}^{o p t}\left(\lambda_{i} ; \theta_{i}\right)\right]
$$


Both inequalities, (17) and (18), should be satisfied for the existence of an equilibrium with partnerships.

The necessary and sufficient conditions for the existence of a $\lambda_{i}$ for every $\theta_{i}$ such that the right hand sides of (17) and (18) are greater than the respective left hand sides depend on a complex set of parameters. However, applying the reasoning in the proofs of propositions 3.3 and 3.5 we can show that the following result holds:

Proposition 4.2 For a given level of long-term productivity level $\theta_{i}$, the higher the pledgeability level of a prospected joint venture, $\lambda_{i}$, the higher is the probability of the existence of a profitable joint venture.

The interpretation of this result is similar to the interpretation of the result we obtained in the previous section. When the amount which can be invested in long-term technology is low, it is not beneficial to form a partnership. Therefore, when the economy-wide enforce-ability is low it is not optimal for entrepreneurs with low financial worthiness to switch from short-term investment to longterm investment during the second period of their lifetime.

\subsubsection{Young Entrepreneur's Program and General Equilibrium}

A young entrepreneur decides which technology paths to follow ((Long-term),(Short-term,Long-term), and (Short-term,Short-term)) at the beginning of his life-time. Therefore, the technology choice problem of a young entrepreneur is:

$$
\max \left\{V^{S S}\left(x_{1}^{o p t}, x_{2}^{o p t}\right), V^{S L}\left(x_{1}^{o p t}, k_{2}^{o p t}\right), V^{L L}\left(k_{1}^{o p t}\right)\right\}
$$

$V^{S S}\left(x_{1}^{o p t}, x_{2}^{o p t}\right), V^{S L}\left(x_{1}^{o p t}, k_{2}^{o p t}\right)$, and $V^{L L}\left(k_{1}^{o p t}\right)$ represent life-time value functions associated with being a short-term entrepreneur in both periods, a short-term entrepreneur in the first period and switching to being a long-term entrepreneur during the second period, and being a long-term entrepreneur in both periods, respectively.

As in section 3, for every pledgeability level $\lambda_{i}$ we derive threshold levels to determine lifetime technology paths. Except this time we need to derive two of them, namely $\overline{\theta_{1}}\left(\lambda_{i}\right)$ and $\overline{\theta_{2}}\left(\lambda_{i}\right)$. For a given $\lambda_{i}$, when $\theta_{i} \geq \bar{\theta}_{2}\left(\lambda_{i}\right)$ the entrepreneur $i$ chooses to become an investor using the technology-L at 
the beginning of his lifetime. If $\overline{\theta_{1}}\left(\lambda_{i}\right) \leq \theta_{i} \leq \overline{\theta_{2}}\left(\lambda_{i}\right)$, during the first period the entrepreneur chooses to operate the technology-S; however, he switches to the technology-L when he is middle-aged. And, finally entrepreneurs with $\theta_{i} \leq \bar{\theta}_{1}\left(\lambda_{i}\right)$ choose to operate the technology-S throughout their life-cycle. We can obtain the following results regarding the fraction of long-term projects undertaken in the economy:

Proposition 4.3 The aggregate investment in technology-L projects is greater in an economy where partnership formations are allowed relative to an economy where partnership formations are not allowed.

In the current set-up, after building up collateral, entrepreneurs have a second chance to invest long-term. Therefore, aggregate long-term investment is higher now relative to the no-partnerships economy presented in the previous section.

Proposition 4.4 The total fraction of young entrepreneurs starting up businesses in technology- $L$ is smaller when partnership formations are allowed.

Due to the collateral effect some entrepreneurs are better off starting up with the technology-S and later on switching to use the technology-L during their middle-age.

\section{Quantitative Analysis}

In this section we study the quantitative properties of the model. Our objective is to analyze the effects of financial contract enforcement on aggregate long-term investment and macroeconomic performance, measured in terms of total output, in a parameterized version of the model. In this respect we identify two channels through which financial contract enforcement influences the total factor productivity: (1) The aggregate investment composition between short-term investment and long-term investment, and (2)the aggregate distribution of capital across entrepreneurs. We measure the quantitative macro effects of the reallocation of entrepreneurial talent from short-term investment to long-term investment, and also the reallocation of physical capital from large firms to small firms as a response to a rise in the level of financial contract enforcement. Subsection 1 presents the parameterization of the model for the U.S. data, and subsection 2 the parameterization of the model for the Turkish data and a 
counterfactual policy experiment where we ask how much aggregate long term investment and total output would rise if the calibrated value of financial contract enforcement of the Turkish economy would improve to the level of financial contract enforcement of the U.S. economy.

\subsection{Parameterization: The U.S. Economy}

We parameterize the model to match some moments we observe in the U.S. data. Table 3 lists the parameter values which we use to match the statistics listed in table 2 as the steady state values of the model $^{8}$. In table 3, the share of entrepreneurs is chosen following Quadrini [23]. Private debt to output ratio is from Antunes et al. [2]. We extract the firm level data from Compustat North America. The breakdown of long-term and short-term investment is not observable in Compustat; however, the breakdown of long-term and short-term liabilities is frequently reported. Many studies such as Demirguc and Maksimovic [10], and Aghion et al. [1], suggest that long-term investment can be undertaken the least costly if firms have access to long-term investable funds. By certainly accepting the limitations imposed, we proxy the intensity to invest long-term at the firm level with the observed long-term liabilities reported in Compustat data. We use the following cross-sectional averages over the 1997-2006 time period to proxy the investment structure: Aggregate Long-Term (L.T.) Debt to Total Assets ratio to proxy the aggregate long-term investment intensity; Average Long-Term Debt to Total Assets ratio for large scale firms to proxy the aggregate long-term investment intensity for large scale firms; Average Long-Term Debt to Total Assets ratio for medium size firms to proxy the aggregate long-term investment intensity for medium size firms; Average Long-Term Debt to Total Assets ratio for small firms to proxy the aggregate long-term investment intensity for small firms; the ratio between Total Outstanding Debt by Large Firms and Aggregate Debt, the ratio between Total Outstanding Debt by Medium Size Firms and Aggregate Debt, and the ratio between Total Outstanding Debt by Small Firms and Aggregate Debt. Firm size classes are defined according to their employment levels in the following way: Small firms have less than 500 employees, medium size firms have less than 5000 and more than 500 employees and large firms have more than 5000 employees. The classification of small, medium size and large in the model is according to the level of financial pledgeability. Small firms in the model are firms owned by entrepreneurs for whom the level of financial pledgeability is

\footnotetext{
${ }^{8}$ Column 2 reports the steady state values of the model with partnership formations and column 3 reports the steady state values of the model without partnership formations.
} 
low $\left(\lambda_{j} \leq \lambda^{*}\left(z_{j}\right)\right)$. Medium size firm owners are taken as the entrepreneurs with intermediate level of pledgeability $\left(\lambda^{*}\left(z_{j}\right) \leq \lambda_{j} \leq \lambda^{* *}\right)$. And large firm owners are high pledgeability entrepreneurs who have $\lambda_{j} \geq \lambda^{* *}$. Short term interest rates are calculated using the historic annual average rates (19902008) of 3-month U.S treasury bills, and long-term interest rates using the historic annual average rates (1990-2008) of 5-year U.S treasury bills.

The values assigned to model parameters are listed in table 5. Columns 3 and 4 show parameter values of the model with and without partnerships respectively. We assume that cumulative distribution of long-term project quality is given by $F(\theta)=\theta^{1 / \kappa}$ with support $[0, \bar{\theta}]$, and cumulative distribution of financial pledgeability is given by $G(\lambda)=\lambda^{1 / \sigma}$ with support $[a, \bar{\lambda}]$ for short-term pledgeability and with support $[0, \bar{\lambda}]$ for long-term pledgeability. Calibrated values of $\kappa$ and $\sigma$ are greater than one, which implies that the distribution is concentrated at low pledgeability and low ability entrepreneurs. We define the model period to be 25 years.

The share of financiers is calibrated such that the population share of non-entrepreneurs of the U.S. economy can be captured. The probability of facing a liquidity shock is calibrated such that the aggregate long-term (L.T.) debt to total assets ratio of the model matches the same variable for the U.S. economy. We assume that financiers have log preferences $(u(c)=\ln (c))$, and the entrepreneurial production technologies are Cobb-Douglas. The remaining parameters in table 5 are calibrated to match the remaining target moments listed in table 4 .

Cagetti and De Nardi [7] and Antunes et al. [2] define a contract enforcement parameter similar to the one we introduced in section 2. Cagetti and De Nardi [7] calibrate the value of the contract enforcement parameter for the U.S. economy as 0.25, and Antunes et al. [2] calibrate it as 0.26. The value of contract enforcement $(1 / \zeta)$ in our model is 0.32 when partnerships are allowed and 0.34 when partnerships are not allowed. The reason for the difference between their calibrated values of financial contract enforcement and ours is that in our model limited contract enforcement not only affects firm size but also the investment horizon composition of individual entrepreneurs. Due to this important structural distinction between the two settings the calibrated values of contract enforcement are different. As we can observe in table 4 both models match targeted U.S. baseline statistics well along a number of dimensions ${ }^{9}$.

\footnotetext{
${ }^{9}$ In the Appendix B a quantitative experiment can be found where we study the quantitative implications of the changes in the level financial contract enforcement on U.S. aggregate economic performance
} 


\subsection{Counterfactual Experiments: The Case of Turkey}

It is crucial to study the behavior of the model for a relatively lower enforcement economy to fully illustrate the effects of financial contract enforcement on economic development. For this purpose in this section, at first we re-calibrate the steady state equilibrium of the model to match key aggregate statistics of the Turkish economy. Turkey is a fast growing developing economy on the verge of the integration to the European Union; however, its financial system suffers from limited financial contract enforcement. World Bank [3] reported the legal rights scores of Turkey ranging from 1 to 4 between 2001-2009, whereas the legal rights scores of the U.S. as ranging from 7 to 8 for the same time period ${ }^{10}$.

The benchmark calibration results for the Turkish economy can be found in tables 9 and 10. The aggregate variables for the Turkish economy are obtained in the following way. The annual interest rates are targeted to be $2 \%$ for the short-term interest rate, and $6 \%$ for the long-term interest rate. The Turkish economy experienced very high real interest rates over the past few decades (over $15 \%$ annual). Therefore, for comparability of the two economies in a meaningful way we choose no to use Turkish real interest rates for the benchmark calibration. The share of entrepreneurs is chosen as $2 \%$ following Cetindamar [8]. Private debt to output ratio is 0.2 which we obtained from IMF's International Financial Statistics. Firm level data is from International Financial Corporation and follows the sample statistics in Demirguc and Maksimovic [10]. Table 7 lists the target moments and the behavior of the model with (2nd column) and without (3rd column) partnership formations.

After calibrating the steady state equilibrium of the model for the Turkish economy, we conduct two counterfactual policy experiments. In the first exercise, we replace Turkey's baseline contract enforcement level (0.13 for the partnership economy, and 0.14 for the no-partnership economy) with the contract enforcement level of the U.S. (0.32 for the partnership economy, and 0.34 for the nopartnership economy), keeping other parameters as in the benchmark calibration of Turkey. Our main objective in this exercise is to study how the per capita output would be if the financial contract enforcement of the Turkish economy was as in the United States. Table 11 reports the results. We can observe that a structural change in financial contract enforcement has an important impact (a 13-15\% increase in per capita output) on economic performance.

We study the effects of financial contract enforcement on economic performance due to changes

\footnotetext{
${ }^{10}$ The legal rights index ranges from 1 to 10 where higher scores indicate better enforcement of collateral and bankruptcy laws.
} 
in establishment size distribution (misallocation of physical capital across its users) and changes in long-term investment (misallocation of talent across investment projects) in isolation. Table 12 reports the results for the case when entrepreneurs' investment structure remains the same before and after the improvement in financial contract enforcement. Table 12 implies that a significant portion of the aggregate effects of financial contract enforcement is due to the changes at entrepreneurial investment horizon composition. About 31 to $33 \%$ of the aggregate effects of financial contract enforcement are due to the changes in long-term technology use. Table 13 summarizes the breakdown of the implications of financial contract enforcement due to improvements in the firm size distribution and due to the change in long-term investment rate. We conclude that financial contract enforcement is important for a country's long-term technology adoption as well as its investment size distribution.

In this quantitative analysis the cost of increasing the quality of financial contract enforcement, is set to zero as in Antunes et al. [2]. We understand the limitations of this approach. However, the emphasis of this paper is not on studying the absolute effects financial contract enforcement on macroeconomic performance. Our main research question is to uncover the relative effects of technology choice on macroeconomic development when financial contract enforcement rises from relatively low to relatively higher levels. Therefore, we expect this benchmark specification to be relatively less harmful for our qualitative as well as quantitative results.

\section{Conclusion}

We have developed a framework to study the effects of limited contract enforcement on entrepreneurial technology choice and economic development. Our study shows that limited contract enforcement not only affects the aggregate output of an economy but also its long-term technology use. Key analytical results of the paper have suggested that when financial contract enforcement is weak, the plant size and long-term technology investment are positively correlated with entrepreneurial financial pledgeability. "Collateral building" channel through which the strength of contract enforcement becomes crucial for the level of economic development is an important theoretical contribution of the paper. Our analysis shows that in a high financial contract enforcement economy, long-term technology investment is more profitable since the need for short-term collateral is not as high as in an economy with weak financial contract enforcement. If financial contract enforcement is too weak in an economy, 
productive entrepreneurship through long-term investment prevails only when the initial investment size is sufficiently high, creating a complementarity between the establishment size and the long-term technology use.

We calibrate the steady-state equilibrium of the model to match key aggregate statistics of the U.S. and the Turkish economy. The quantitative analysis have indicated that variations in economy-wide contract enforcement parameter have sizeable effects on the plant size distribution, and on the fraction of entrepreneurs employing the long-term technology. The changes in the long-term technology use feeds back into the level of economic development. The counterfactual experiments have shown that if the level of financial contract enforcement of the Turkish economy was hypothetically changed to the level of financial contract enforcement of the United States, the Turkish output would rise by 13-15\%. About one third of this variation is due to the feedback effects generated by the rise in entrepreneurial long-term technology use which we is the central contribution of our paper.

Finally, our analytical and quantitative findings confirm the predictions by Baumol [4]. The allocation of resources away from unproductive forms of entrepreneurship towards productive entrepreneurship matters for the level of a society's economic development process. This paper shows that institutional development in financial contract enforcement is an effective way for allocating entrepreneurs to productive areas of investment.

\section{References}

[1] P. Aghion, G.M. Angeletos, A. Banerjee, and K. Manova. Volatility and growth: Credit constraints and productivity-enhancing investment. Journal of Monetary Eonomics, 57, 2010.

[2] A. Antunes, T. Cavalcanti, and A. Villamil. The effect of financial repression and enforcement on entrepreneurship and economic development. Journal of Monetary Economics, 55, 2008.

[3] The World Bank. Doing Business 2001-2009. Washington, DC: World Bank, 2009.

[4] W.J. Baumol. Entrepreneurship: Productive, unproductive, and destructive. Journal of Political Economy, 98, 1990.

[5] F. Buera, J. Kabora, and Y. Shin. The macroeconomics of microfinance. Working Paper, 2011. 
[6] F. Buera and Y. Shin. Finance and development: A tale of two sectors. forthcoming American Economic Review, 2011.

[7] M. Cagetti and M. De Nardi. Entrepreneurship, frictions and wealth. Journal of Political Economy, 114, 2006.

[8] D. Cetindamar. Policy issues for turkish entrepreneurs. International Journal of Entrepreneurship and Innovation Management, 5, 2005.

[9] T. Cooley, R. Marimon, and V. Quadrini. Aggregate consequences of limited contract enforceability. Journal of Political Economy, 112, 2004.

[10] A. Demirguc-Kunt and V. Maksimovic. Institutions, financial markets and firm debt maturity. Journal of Financial Economics, 54, 1999.

[11] T. Dunne. Plant age and technology use in u.s. manufacturing industries. The RAND Journal of Economics, 25, 1994.

[12] D.S. Evans and B. Jovanovic. An estimated model of entrepreneurial choice under liquidity constraints. Journal of Political Economy, 97, 1989.

[13] C.T. Hsieh and P.J. Klenow. Misalloaction and manufacturing tfp in china and india. Quarterly Journal of Economics, 124, 2009.

[14] E. Hurst and A. Lusardi. Liquidity constraints, wealth accumulation and entrepreneurship. Journal of Political Economy, 112, 2004.

[15] T. Kehoe and D. Levine. Debt constrained asset markets. Review of Economic Studies, 60, 1993.

[16] M.R. Kelley and H. Brooks. External learning opportunities and the diffusion of process innovations to small firms. Technological Forecasting and Social Change, 39, 1991.

[17] R.E. Kihlstrom and J.J. Laffont. A general equilibrium theory of firm formation based on risk aversion. Journal of Political Economy, 87, 1979.

[18] N. Kiyotaki and J. Moore. Credit cycles. Journal of Political Economy, 105, 1997.

[19] Jr.R.E. Lucas. On the size distribution of business firms. Bell Journal of Economics, 9, 1978. 
[20] A.F. Newman. Risk-bearing and entrepreneurship. Journal of Economic Theory, 137, 2007.

[21] S.C. Parker. Law and the economics of entrepreneurship. Comparative Labor Law and Policy Journal, 28, 2007.

[22] R. La Porta, F. Lopes de Silanes, A. Shleifer, and R. Vishny. Law and finance. Journal of Political Economy, 106, 1998.

[23] V. Quadrini. The importance of entrepreneurship for wealth concentration and mobility. The Review of Income and Wealth, 45, 1999.

[24] E. Quintin. Limited enforcement and the organization of production. Journal of Macroeconomics, $30,2008$.

[25] D. Restuccia and R. Rogerson. Policy distortions and aggregate productivity with heterogeneous plants. Review of Economic Dynamics, 11, 2008.

[26] A.A. Romeo. Interindustry and interfirm differences in the rate of diffusion of an innovation. Review of Economics and Statistics, 57, 1975.

[27] J. Schumpeter. The Theory of Economic Development. 1911.

[28] P. Wang, N. Jiang, and H. Wu. Ability heterogeneity, entrepreneurship and growth. Working Paper, 2007.

[29] S.N. Wiggens. Entrepreneurial enterprises, endogenous ownership and limits to firm size. Economic Inquiry, 33, 1995. 


\section{Appendix A. Proofs}

Proof of Lemma 3.2.(1) The left hand side of (9) is monotonically increasing in $\lambda_{j}$ and $z_{j}$ and the right hand side is constant which implies the result obtained in lemma 3.2.1. (2) When constraints (8) and (11) are not binding, the first order conditions yield the following optimum capital investment levels:

$$
\begin{aligned}
& s^{\prime}\left(x_{1}^{* *}\right)=R_{1} \quad \Rightarrow \quad x_{1}^{o p t}=x_{1}^{* *}=\left(\frac{\alpha z_{j} A}{R_{1}}\right)^{\frac{1}{1-\alpha}} \\
& \ell^{\prime}\left(k^{* *}\right)=R_{2} \Rightarrow k^{o p t}=k^{* *}=\left(\frac{\alpha \theta_{j}}{R_{2}}\right)^{\frac{1}{1-\alpha}}
\end{aligned}
$$

When constraints (8) and (11) are binding then first order conditions yield:

$$
\begin{aligned}
& x_{1}^{o p t}=x_{1}^{*}=\left(\frac{\lambda_{j} z_{j} A}{\zeta R_{1}}\right)^{\frac{1}{1-\alpha}} \\
& k^{o p t}=k^{*}=\left(\frac{\lambda_{j} \theta_{j}}{\zeta R_{2}}\right)^{\frac{1}{1-\alpha}}
\end{aligned}
$$

Where $x_{1}^{* *}>x_{1}^{*}$ and $k^{* *}>k^{*}$ when $\lambda_{j} \geq \lambda^{* *} \equiv \zeta \alpha$. The result in lemma 3.2.2. follows. The first period shortterm investment works as a collateral for the second period short-term investment. Therefore, $\lambda^{* *}>\lambda^{*}\left(z_{b}\right)$.

Proof of Lemma 3.4. The right hand side of (9) is monotonically decreasing in $z_{j}$ (and in $\lambda_{j}$ ) whereas the left hand side is constant (monotonically increasing in $\lambda_{j}$ ). For $\lambda_{j} \geq \lambda^{*}\left(z_{j}\right)$ constraint (9) is non-binding. Therefore, $h\left(\lambda_{j}, z_{j}\right)$ is non-decreasing in $z_{j}$ and $\lambda_{j}$.

Proof of Proposition 3.5. First consider the effect of pledgeability on the lifetime value function associated with short-term investment for an entrepreneur $j$. Consider the inequality (9), which determines the second period investment of an entrepreneur with a short-term horizon. Using the optimum (constrained) first period short-term investment level, we can re-write (9) in implicit function form as;

$$
H\left(x_{2}, \lambda_{j}^{S}\right) \equiv \frac{\lambda_{j}^{S}}{\zeta} A x_{2}^{\alpha}-R_{1}\left[\left(1-\frac{\lambda_{j}^{S}}{\zeta}\right)\left(z_{j} A\right)^{\frac{1}{1-\alpha}} R_{1}\left(\frac{\lambda_{j}^{S}}{\zeta R_{1}}\right)^{\frac{\alpha}{1-\alpha}}\right]=0
$$

An entrepreneur with a low level financial pledgeability invests all his first period income into the second period short-term investment opportunity. Therefore,

$$
\frac{\partial V^{S}\left(x_{1}^{*}, x_{2}^{*}\right)}{\partial \lambda}=\frac{\partial V^{S}}{\partial x_{2}} \frac{\partial x_{2}}{\partial \lambda}
$$


By defining $\gamma\left(\lambda_{j}^{S}\right) \equiv\left(1-\frac{\lambda_{j}^{S}}{\zeta}\right)\left(\lambda_{j}^{S}\right)^{\frac{\alpha}{1-\alpha}}$ we can derive,

$$
\frac{\partial x_{2}}{\partial \lambda}=-\frac{\partial H / \partial \lambda}{\partial H / \partial x_{2}}=\frac{A x_{2}^{\alpha}+\left(z_{j} A\right)^{\frac{1}{1-\alpha}} R_{1}^{\frac{1-2 \alpha}{1-\alpha}} \gamma^{\prime}\left(\lambda_{j}^{S}\right)}{R_{1}-\lambda_{j}^{S} \alpha A x_{2}^{\alpha_{1}}}
$$

and

$$
\frac{\partial V^{S T}}{\partial x_{2}}=\alpha A x_{2}^{\alpha-1}-R_{1}
$$

where $\gamma^{\prime}\left(\lambda_{j}^{S}\right)$ is the derivative of $\gamma\left(\lambda_{j}^{S}\right)$ with respect to $\lambda_{j}$. Hence, $\frac{\partial V^{S}\left(x_{1}^{*}, x_{2}^{*}\right)}{\partial \lambda}$ can characterized as:

$$
\frac{\partial V^{S}\left(x_{1}^{*}, x_{2}^{*}\right)}{\partial \lambda}=\underbrace{\left(\frac{\alpha A x_{2}^{\alpha-1}-R_{1}}{R_{1}-\lambda_{j}^{S} \alpha A x_{2}^{\alpha}}\right)}_{\Sigma\left(\lambda_{j}^{S}\right)}\left(A x_{2}^{\alpha}+\left(z_{j} A\right)^{\frac{1}{1-\alpha}} R_{1}^{\frac{1-2 \alpha}{1-\alpha}} \gamma^{\prime}\left(\lambda_{j}^{S}\right)\right)
$$

$\lambda_{j} \leq \lambda^{* *}\left(z_{j}\right)$ ensures that $\Sigma\left(\lambda_{j}^{S}\right)$ is positive.

Now consider the financial constraint (11) which determines the investment size of a constrained entrepreneur with a long-term horizon. The effect of pledgeability on the value function associated with long-term investment can be derived as:

$$
\frac{\partial V^{L}\left(k^{*}\right)}{\partial \lambda}=\frac{\partial V^{L}}{\partial k} \frac{\partial k}{\partial \lambda}=\gamma^{\prime}\left(\lambda_{j}^{L}\right) \theta_{j}\left(\frac{1}{1-\alpha}\right)^{\frac{1}{1-\alpha}}
$$

The effect of pledgeability on long-term investment intensity can be recovered by comparing (25) and (26). That is firms choose to invest short-term if:

$$
\Sigma\left(\lambda_{j}^{S}\right)\left(\frac{A x_{2}^{\alpha}}{\gamma^{\prime}\left(\lambda_{j}^{L}\right)}+\frac{A^{\frac{1}{1-\alpha}} R_{1}^{\frac{1-2 \alpha}{1-\alpha}} \gamma^{\prime}\left(\lambda_{j}^{S}\right)}{\gamma^{\prime}\left(\lambda_{j}^{L}\right)}\right) \geq \theta_{j}\left(\frac{1}{1-\alpha}\right)^{\frac{1}{1-\alpha}}
$$

Remembering $\lambda$ is bounded below by a for low pledgeability entrepreneurs; if the entrepreneur has a short-term investment horizon, we can observe that,

$$
\begin{aligned}
\lim _{\lambda_{j} \rightarrow 0} \Sigma\left(\lambda_{j}^{S}\right) & =\lim _{\lambda_{j} \rightarrow 0}\left(\frac{\alpha A x_{2}^{\alpha-1}-R_{1}}{R_{1}-a \alpha A x_{2}^{\alpha}}\right)=M \\
\lim _{\lambda_{j} \rightarrow 0} \gamma^{\prime}\left(\lambda_{j}^{S}\right) & =\lim _{\lambda_{j} \rightarrow 0}\left[\frac{\alpha}{1-\alpha}\left(\lambda_{j}+a\right)^{\frac{2 \alpha-1}{1-\alpha}}(1-\lambda+a)-\left(\lambda_{j}+a\right)^{\frac{\alpha}{1-\alpha}}\right]=N
\end{aligned}
$$

Where $M$ and $N$ are constants. We can also obtain:

$$
\lim _{\lambda_{j} \rightarrow 0} \gamma^{\prime}\left(\lambda_{j}^{l}\right)=\lim _{\lambda_{j} \rightarrow 0}\left[\frac{\alpha}{1-\alpha}\left(\lambda_{j}\right)^{\frac{2 \alpha-1}{1-\alpha}}(1-\lambda)-\left(\lambda_{j}\right)^{\frac{\alpha}{1-\alpha}}\right]=0
$$


If $\lambda_{j}$ is close enough to the low end of the pledgeability distribution, the left hand side of the inequality

diverges to positive infinity, whereas the right hand side converges to a constant. $\theta^{l}\left(\lambda_{j}=0\right)=0$, which implies that for very low levels of financial pledgeability, local improvements in the level of pledgeability do not result with any changes in investment horizon composition. For $\lambda_{j}$ high enough,

$$
\Sigma\left(\lambda_{j}^{S}\right)\left(\frac{A x_{2}^{\alpha}}{\gamma^{\prime}\left(\lambda_{j}^{l}\right)}+\frac{A^{\frac{1}{1-\alpha}} R_{1}^{\frac{1-2 \alpha}{1-\alpha}} \gamma^{\prime}\left(\lambda_{j}^{S}\right)}{\gamma^{\prime}\left(\lambda_{j}^{L}\right)}\right) \leq \theta_{j}\left(\frac{1}{1-\alpha}\right)^{\frac{1}{1-\alpha}}
$$

holds, in which case local improvements in financial pledgeability leads to increases in long-term investment intensity. Therefore, there exists a critical $\lambda^{c}$, such that for $\lambda_{j} \geq \lambda_{c}$ low pledgeability entrepreneurs become long-term oriented in the face of rising pledgeability as it is the case for intermediate level financial pledgeability entrepreneurs. The results in part (b) can be obtained in a similar way.

Proof of Proposition 3.6. $\frac{\partial \lambda^{* *}}{\partial(1 / \zeta)}<0$ follows from lemma 3.2, and $\frac{\partial \lambda^{c}}{\partial(1 / \zeta)}<0$ from proposition 3.5.

Proof of Proposition 3.7. Simple comparative statics at $x_{1}^{*}, x_{2}^{*}, x_{1}^{* *}, x_{2}^{* *}, k^{*}$ and $k^{* *}$ shows that for all periods, due to the concavity in investment projects optimum (constrained and unconstrained) short-term and long-term capital demands are decreasing in respective interest rates. As proposition 3.1 shows the share of loanable funds allocated to short-term lending is increasing in short-term interest rate, whereas it is decreasing in long-term interest rate. Neither capital, nor the technological level evolve in the economy. Therefore, the economy is in steady state from the beginning of time. The result in proposition 3.7 follows. $\square$

Proof of Proposition 4.1. Remember that productivity and pledgeability levels of a joint venture are determined as $\theta_{v}=\min \left\{\theta_{p}, \theta_{s}\right\}$ and $\lambda_{v}=\min \left\{\lambda_{p}, \lambda_{s}\right\}$ respectively, and $\theta_{v}$ and $\lambda_{v}$ jointly determine the surplus generated by the partnership. Keeping this in mind suppose there is a joint venture in equilibrium with the following partner characteristics: $\left(\theta_{i}, \lambda_{i}\right)_{t}$ and $\left(\theta_{i}, \lambda_{i}\right)_{t+1}$. We should check whether unilateral deviations from this match can create extra surplus for any of the partners. Take the middle aged agent $\left(\theta_{i}, \lambda_{i}\right)_{t}$ : Keeping $\theta_{i}$ constant, we know that the middle-aged entrepreneur $i$ will not choose to contract with any young agent $z$ with $\lambda_{z}<\lambda_{i}$, and no young agent $w$ with $\lambda_{w}>\lambda_{i}$ is going to accept a partnership offer from $i$. The analog result holds when we keep $\lambda_{i}$ constant and vary $\theta$. The proposed match between "identical twins" across two generations is thus an equilibrium outcome. 


\section{Appendix B. Quantitative Analysis}

\section{Benchmark Calibration (U.S.)}

Table 2: Basic Statistics U.S. against Model

\begin{tabular}{c|c|c|c}
\hline \hline & U.S. & Model w. Partner. & Model w/o Partner. \\
\hline \hline & & & \\
Annual Interest Rate (\%) (S.T.) & 2.0 & 1.97 & 1.91 \\
Annual Interest Rate (\%) (L.T.) & 6.0 & 5.71 & 5.61 \\
\% of Entrepreneurs & 9 & 9 & 2.04 \\
Private Debt to Output Ratio (Agg.) & 1.98 & 2.03 & 0.31 \\
L.T. Debt to Total Assets Ratio (Agg.) & 0.37 & 0.32 & 0.29 \\
L.T. Debt to Total Assets Ratio (Avg. for Sm.) & 0.33 & 0.30 & 0.34 \\
L.T. Debt to Total Assets Ratio (Avg. for Md.) & 0.38 & 0.35 & 0.52 \\
L.T. Debt to Total Assets Ratio (Avg. for Lg.) & 0.48 & 0.51 & 0.18 \\
Debt of Sm. (Agg.) to Debt (Agg.) & 0.21 & 0.24 & 0.49 \\
Debt of Md. (Agg.) to Debt (Agg.) & 0.45 & 0.45 & 0.33 \\
Debt of Lg. (Agg.) to Debt (Agg.) & 0.34 & 0.31 & \\
\hline
\end{tabular}

The entrepreneurial share is from Quadrini [23]. Private Debt to Output Ratio is from Antunes [2]. Firm level data is from Compustat North America with 1997-2006 averages. Avg. stands for average, Agg. for aggregate, Sm. for Small, Md. for Medium Size, Lg. for Large. Firm size classes are defined according to the employment level in the following way: Small firms have less than 500 employees, medium size firms have less 5000 and more than 500 employees and large firms have more than 5000 employees. The classification of small, medium size and large in the model is according to the level of financial pledgeability. 
Table 3: Parameter Values for the Baseline Economy (U.S.)

\begin{tabular}{c|c|c|c}
\hline \hline \multirow{2}{*}{ Parameter } & Description & Partner. & No Partner. \\
& \% of Financiers & 91 & 91 \\
\hline \hline & \% of Liquidity Shock & 0.18 & 0.14 \\
$1-\pi$ & Contract Enforcement & 0.32 & 0.34 \\
$1 / \zeta$ & DRS of Investment Projects & 0.23 & 0.24 \\
$(1-\alpha)$ & Product. of S.T. Projects & 3.37 & 3.14 \\
$A$ & Prob. of a Good Prod. Shock & 0.63 & 0.61 \\
$\gamma$ & $\bar{z}=\gamma z_{g}+(1-\gamma) z_{b}$ & 1.35 & 1.29 \\
$\bar{z}$ & Distribution of Ability & $\kappa=4.28$ & $\kappa=4.19$ \\
$F(\theta)=\theta^{\frac{1}{\kappa}}$ & Upper Bound for Ability & 9.18 & 9.21 \\
$\bar{\theta}$ & Distribution of pledgeability & $\sigma=1.99$ & $\sigma=1.92$ \\
$G(\lambda)=\lambda^{\frac{1}{\sigma}}$ & Upper Bound for Financial pledgeability & 0.82 & 0.85 \\
$\bar{\lambda}$ & \multicolumn{2}{|c}{} \\
\hline \hline
\end{tabular}

The lower bound of short-term financial pledgeability $a$ is normalized to be 0.02 . This value is not binding for the benchmark calibration of the model.

\section{Policy Analysis (U.S.)}

Table 4: The Effects of Limited Contract Enforcement (U.S.)

\begin{tabular}{c|c|c|c|c}
\hline \hline & \multicolumn{3}{|c}{ Changes in Enforcement } \\
\cline { 2 - 4 } & $\zeta_{P}=1 / 0.32$ & $\zeta_{P}^{\prime}=2 \times 1 / 0.32$ & $\zeta_{N P}=1 / 0.34$ & $\zeta_{N P}^{\prime}=2 \times 1 / 0.34$ \\
& & & & \\
Annual Interest Rate (\%) (S.T.) & 1.97 & 1.99 & 1.91 & 1.92 \\
Annual Interest Rate (\%) (L.T.) & 5.71 & 5.62 & 5.61 & 5.49 \\
Output Per Capita (Aggregate) & 100 & 94 & 100 & 91 \\
Out. Per Capita $\left(\lambda_{j} \geq \lambda^{* *}\right)$ & 40 & 39 & 41 & 39 \\
Out. Per Capita $\left(\lambda^{*}\left(z_{j}\right) \leq \lambda_{j} \leq \lambda^{* *}\right)$ & 39 & 37 & 38 & 17 \\
Out. Per Capita $\left(\lambda_{j} \leq \lambda^{*}\left(z_{j}\right)\right)$ & 21 & 18 & 21 & 0.69 \\
S.T. to L.T. Out. Ratio $($ Agg.) & 0.65 & 0.68 & 0.68 & 0.54 \\
S.T. to L.T. Out. Ratio $\left(\lambda_{j} \geq \lambda^{* *}\right)$ & 0.55 & 0.56 & 0.53 & 0.67 \\
S.T. to L.T. Out. Ratio $\left(\lambda^{*}\left(z_{j}\right) \leq \lambda_{j}<\lambda^{* *}\right)$ & 0.61 & 0.64 & 0.62 & 0.78 \\
S.T. to L.T. Out. Ratio $\left(\lambda_{j} \leq \lambda^{*}\left(z_{j}\right)\right)$ & 0.73 & 0.76 & 0.75 & \\
\hline \hline
\end{tabular}

All the reported results are for aggregate variables, e.g. "Out. Per Capita $\left(\lambda^{*}\left(z_{j}\right) \leq \lambda_{j} \leq \lambda^{* *}\right)$ " stands for aggregate output produced by all "large"-high pledgeability entrepreneurs. $\zeta_{P}$ and $\zeta_{N P}$ stand for the economy-wide enforcement parameter for the partnership and the no-partnership economy respectively. 
Table 5: The Effects of Limited Contract Enforcement (U.S.) (With Controlling for the Compositional Change)

\begin{tabular}{c|c|c|c|c}
\hline \hline & \multicolumn{3}{|c}{ Changes in Enforcement } \\
\cline { 2 - 4 } & $\zeta_{P}=1 / 0.32$ & $\zeta_{P}^{\prime}=2 \times 1 / 0.32$ & $\zeta_{N P}=1 / 0.34$ & $\zeta_{N P}^{\prime}=2 \times 1 / 0.34$ \\
& & & & \\
\hline \hline & & & 1.91 & 1.91 \\
Annual Interest Rate (\%) (S.T.) & 1.97 & 5.99 & 5.53 \\
Annual Interest Rate (\%) (L.T.) & 5.71 & 5.64 & 93 \\
Output Per Capita (Aggregate) & 100 & 95 & 100 & 39 \\
Out. Per Capita $\left(\lambda_{j} \geq \lambda^{* *}\right)$ & 40 & 39 & 41 & 36 \\
Out. Per Capita $\left(\lambda^{*}\left(z_{j}\right) \leq \lambda_{j} \leq \lambda^{* *}\right)$ & 39 & 38 & 38 & 0.69 \\
Out. Per Capita $\left(\lambda_{j} \leq \lambda^{*}\left(z_{j}\right)\right)$ & 21 & 18 & 21 & 0.54 \\
S.T. to L.T. Out. Ratio $($ Agg.) & 0.65 & 0.67 & 0.68 & 0.65 \\
S.T. to L.T. Out. Ratio $\left(\lambda_{j} \geq \lambda^{* *}\right)$ & 0.55 & 0.56 & 0.53 & 0.77 \\
S.T. to L.T. Out. Ratio $\left(\lambda^{*}\left(z_{j}\right) \leq \lambda_{j}<\lambda^{* *}\right)$ & 0.61 & 0.63 & 0.62 & 0.75 \\
S.T. to L.T. Out. Ratio $\left(\lambda_{j} \leq \lambda^{*}\left(z_{j}\right)\right)$ & 0.73 & 0.75 & & \\
\hline \hline
\end{tabular}

Table 6: The Isolation of Effects of Contract Enforcement (Variation from Baseline U.S.)

\begin{tabular}{c|cccc}
\hline \hline & \multicolumn{4}{|c}{ Breakdown of Effects Due (in \%) } \\
\cline { 2 - 5 } & Partnership & Economy & No-Partnership & Economy \\
\hline & Size & Tech. & Size & Tech. \\
& Dist. & Adop. & Dist. & Adop. \\
\hline \hline & & & & 22 \\
Output Per Capita (Aggregate) & 83 & 17 & 78 & 1 \\
Out. Per Capita $\left(\lambda_{j} \geq \lambda^{* *}\right)$ & 99 & 1 & 99 & 33 \\
Out. Per Capita $\left(\lambda^{*}\left(z_{j}\right) \leq \lambda_{j} \leq \lambda^{* *}\right)$ & 50 & 50 & 67 & 25 \\
Out. Per Capita $\left(\lambda_{j} \leq \lambda^{*}\left(z_{j}\right)\right)$ & 99 & 1 & 75 & 1 \\
S.T. to L.T. Out. Ratio $($ Agg.) & 67 & 33 & 99 & 40 \\
S.T. to L.T. Out. Ratio $\left(\lambda_{j} \geq \lambda^{* *}\right)$ & 99 & 1 & 69 & 33 \\
S.T. to L.T. Out. Ratio $\left(\lambda^{*}\left(z_{j}\right) \leq \lambda_{j}<\lambda^{* *}\right)$ & 67 & 33 & 67 & \\
S.T. to L.T. Out. Ratio $\left(\lambda_{j} \leq \lambda^{*}\left(z_{j}\right)\right)$ & 67 & 33 & & \\
\hline \hline
\end{tabular}




\section{Benchmark Calibration (Turkey)}

Table 7: Basic Statistics Turkey against Model

\begin{tabular}{c|c|c|c}
\hline \hline & Turkey & Model & Model w/o Partner. \\
\hline \hline & & & \\
Annual Interest Rate (\%) (S.T.) & 2.0 & 1.91 & 1.87 \\
Annual Interest Rate (\%) (L.T.) & 6.0 & 5.55 & 5.43 \\
\% of Entrepreneurs & 5 & 5 & 5 \\
Private Credit to Output Ratio (Agg.) & 0.20 & 0.22 & 0.25 \\
L.T. Debt to Total Assets (Agg.) & 0.14 & 0.13 & 0.15 \\
L.T. Debt to Total Assets (Avg. of Sm.) & 0.07 & 0.06 & 0.07 \\
L.T. Debt to Total Assets (Avg. of Md.) & 0.09 & 0.10 & 0.10 \\
L.T. Debt to Total Assets (Avg. of Lg.) & 0.20 & 0.23 & 0.24 \\
Debt of Sm. (Agg.) to Debt (Agg.) & 0.20 & 0.22 & 0.23 \\
Debt of Md. (Agg.) to Debt (Agg.) & 0.27 & 0.25 & 0.26 \\
Debt of Lg. (Agg.) to Debt (Agg.) & 0.53 & 0.53 & 0.51 \\
\hline \hline
\end{tabular}

The entrepreneurial share is from Cetindamar [8]. Private Debt to Output Ratio is from IMF's International Financial Statistics. Firm level data is from International Financial Corporation.

Table 8: Parameter Values for the Baseline Economy (Turkey)

\begin{tabular}{c|c|c|c}
\hline \hline \multirow{2}{*}{ Parameter } & Description & Partner. & No Partner. \\
& \% of Financiers & 95 & 95 \\
$\mu$ & \% of Liquidity Shock & 0.20 & 0.17 \\
$1-\pi$ & Contract Enforcement & 0.13 & 0.14 \\
$1 / \zeta$ & DRS of Investment Projects & 0.26 & 0.27 \\
$(1-\alpha)$ & Product. of S.T. Projects & 2.83 & 2.91 \\
$A$ & Prob. of a Good Prod. Shock & 0.53 & 0.52 \\
$\gamma$ & $\bar{z}=\gamma z_{g}+(1-\gamma) z_{b}$ & 1.31 & 1.33 \\
$\bar{z}$ & Distribution of Ability & $\kappa=6.92$ & $\kappa=6.82$ \\
$F(\theta)=\theta^{\frac{1}{\kappa}}$ & Upper Bound for Ability & 6.19 & 6.23 \\
$\bar{\theta}$ & Distribution of pledgeability & $\sigma=2.33$ & $\sigma=2.17$ \\
$G(\lambda)=\lambda_{\bar{\sigma}}^{\frac{1}{\sigma}}$ & Upper Bound for Financial pledgeability & 0.75 & 0.79 \\
$\bar{\lambda}$ & \multicolumn{2}{|l}{} \\
\hline \hline
\end{tabular}

The lower bound of short-term financial pledgeability $a$ is normalized to be 0.02 as in the U.S case. This value is not binding for the benchmark calibration of the model. 


\section{Counterfactual Policy Analysis (Turkey)}

Table 9: The Effects of Limited Contract Enforcement (From Baseline Turkey to Baseline U.S.)

\begin{tabular}{c|c|c|c|c}
\hline \hline & \multicolumn{3}{|c}{ Changes in Enforcement } \\
\cline { 2 - 5 } & $\zeta_{P}^{T}=1 / 0.13$ & $\zeta_{P}^{U S}$ & $\zeta_{N P}^{T}=1 / 0.14$ & $\zeta_{N P}^{U S}$ \\
& & & & \\
\hline \hline & & & & \\
Annual Interest Rate (\%) (S.T.) & 1.91 & 1.95 & 1.87 & 1.90 \\
Annual Interest Rate (\%) (L.T.) & 5.55 & 5.65 & 5.43 & 5.52 \\
Output Per Capita (Aggregate) & 100 & 115 & 100 & 113 \\
Out. Per Capita $\left(\lambda_{j} \geq \lambda^{* *}\right)$ & 35 & 34 & 38 & 37 \\
Out. Per Capita $\left(\lambda^{*}\left(z_{j}\right) \leq \lambda_{j} \leq \lambda^{* *}\right)$ & 38 & 45 & 35 & 41 \\
Out. Per Capita $\left(\lambda_{j} \leq \lambda^{*}\left(z_{j}\right)\right)$ & 27 & 36 & 27 & 35 \\
S.T. to L.T. Out. Ratio $($ Agg.) & 0.89 & 0.81 & 0.92 & 0.84 \\
S.T. to L.T. Out. Ratio $\left(\lambda_{j} \geq \lambda^{* *}\right)$ & 0.74 & 0.74 & 0.75 & 0.75 \\
S.T. to L.T. Out. Ratio $\left(\lambda^{*}\left(z_{j}\right) \leq \lambda_{j}<\lambda^{* *}\right)$ & 0.90 & 0.80 & 0.93 & 0.84 \\
S.T. to L.T. Out. Ratio $\left(\lambda_{j} \leq \lambda^{*}\left(z_{j}\right)\right)$ & 0.94 & 0.81 & 0.95 & 0.83 \\
& & & & \\
\hline \hline
\end{tabular}

$\zeta_{P}^{T}, \zeta_{N P}^{T}, \zeta_{P}^{U S}, \zeta_{N P}^{U S}$ stand for the economy-wide enforcement parameter for the partnership and the nopartnership economy for Turkey and the U.S. respectively.

Table 10: The Effects of Limited Contract Enforcement(From Baseline Turkey to Baseline U.S.) (With Controlling for the Compositional Change)

\begin{tabular}{c|c|c|c|c}
\hline \hline & \multicolumn{3}{|c}{ Changes in Enforcement } \\
\cline { 2 - 5 } & $\zeta_{P}^{T}=1 / 0.13$ & $\zeta_{P}^{U S}$ & $\zeta_{N P}^{T}=1 / 0.14$ & $\zeta_{N S}^{U S}$ \\
\hline \hline & & & & \\
Annual Interest Rate (\%) (S.T.) & 1.91 & 1.96 & 1.87 & 1.92 \\
Annual Interest Rate (\%) (L.T.) & 5.55 & 5.61 & 5.43 & 5.50 \\
Output Per Capita (Aggregate) & 100 & 110 & 100 & 109 \\
Out. Per Capita $\left(\lambda_{j} \geq \lambda^{* *}\right)$ & 35 & 34 & 38 & 37 \\
Out. Per Capita $\left(\lambda^{*}\left(z_{j}\right) \leq \lambda_{j} \leq \lambda^{* *}\right)$ & 38 & 43 & 35 & 39 \\
Out. Per Capita $\left(\lambda_{j} \leq \lambda^{*}\left(z_{j}\right)\right)$ & 27 & 33 & 27 & 33 \\
S.T. to L.T. Out. Ratio $($ Agg.) & 0.89 & 0.86 & 0.92 & 0.90 \\
S.T. to L.T. Out. Ratio $\left(\lambda_{j} \geq \lambda^{* *}\right)$ & 0.74 & 0.74 & 0.75 & 0.75 \\
S.T. to L.T. Out. Ratio $\left(\lambda^{*}\left(z_{j}\right) \leq \lambda_{j}<\lambda^{* *}\right)$ & 0.90 & 0.86 & 0.93 & 0.90 \\
S.T. to L.T. Out. Ratio $\left(\lambda_{j} \leq \lambda^{*}\left(z_{j}\right)\right)$ & 0.94 & 0.91 & 0.95 & 0.93 \\
\hline
\end{tabular}


Table 11: The Isolation of Effects of Contract Enforcement (From Baseline Turkey to Baseline U.S.)

\begin{tabular}{c|cccc}
\hline \hline & \multicolumn{4}{|c}{ Breakdown of Effects Due (in \%) } \\
\cline { 2 - 5 } & Partnership & Economy & No-Partnership & Economy \\
\hline & Size & Tech. & Size & Tech. \\
& Dist. & Adop. & Dist. & Adop. \\
\hline \hline & & & & 31 \\
Output Per Capita (Aggregate) & 67 & 33 & 69 & 1 \\
Out. Per Capita $\left(\lambda_{j} \geq \lambda^{* *}\right)$ & 99 & 1 & 99 & 33 \\
Out. Per Capita $\left(\lambda^{*}\left(z_{j}\right) \leq \lambda_{j} \leq \lambda^{* *}\right)$ & 71 & 29 & 67 & 25 \\
Out. Per Capita $\left(\lambda_{j} \leq \lambda^{*}\left(z_{j}\right)\right)$ & 67 & 33 & 75 & 1 \\
S.T. to L.T. Out. Ratio $($ Agg.) & 37 & 63 & 25 & 67 \\
S.T. to L.T. Out. Ratio $\left(\lambda_{j} \geq \lambda^{* *}\right)$ & 99 & 1 & 99 & 83 \\
S.T. to L.T. Out. Ratio $\left(\lambda^{*}\left(z_{j}\right) \leq \lambda_{j}<\lambda^{* *}\right)$ & 40 & 60 & 33 & 17 \\
S.T. to L.T. Out. Ratio $\left(\lambda_{j} \leq \lambda^{*}\left(z_{j}\right)\right)$ & 23 & 77 & &
\end{tabular}



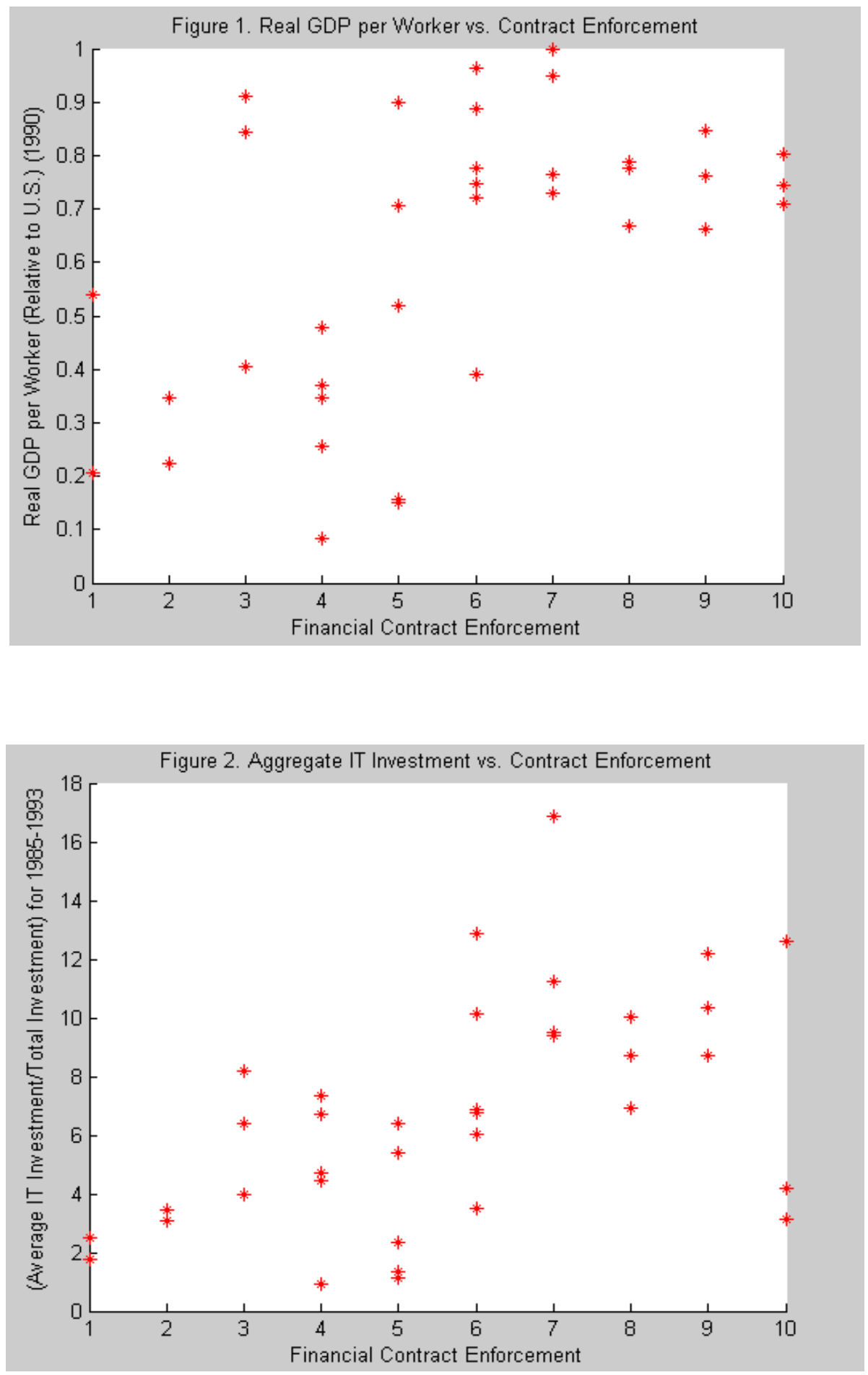

Source: Figure 1: Scatter plot of relative (to U.S.) real GDP per worker (1990) against the level of contract enforcement. GDP data is from Penn World Tables. Contract Enforcement Data is from the World Bank (2001): Legal Rights Index is taken as the measure of contract enforcement. The data ranges from 1 (worst legal rights) to 10 (best legal rights), and measures the quality in the enforcement of collateral and bankruptcy laws.

Figure 2: Scatter plot of the average (1985-1993) annual IT investment as a percentage of total investment, against the level of contract enforcement. IT investment data is from Dewan and Kreamer (1998): Data comprises total values of the revenue paid to vendors for hardware, data communications, software, and services. 